\title{
Sparkle/PM3 for the Modeling of Europium(III), Gadolinium(III), and Terbium(III) Complexes
}

\author{
Ricardo O. Freire, ${ }^{a}$ Gerd B. Rocha ${ }^{b}$ and Alfredo M. Simas ${ }^{*, c}$ \\ ${ }^{a}$ Departamento de Química, CCET, Universidade Federal de Sergipe, 49000-100 São Cristóvão-SE, Brazil \\ ${ }^{b}$ Departamento de Química, CCEN, Universidade Federal da Paraíba, 58059-970 João Pessoa-PB, Brazil \\ 'Departamento de Química Fundamental, CCEN, Universidade Federal de Pernambuco, \\ 50590-470 Recife-PE, Brazil
}

O modelo Sparkle/PM3 é parametrizado para complexos de európio (III), gadolínio (III) e térbio (III). A validação do modelo foi realizada utilizando noventa e seis complexos de Eu(III), setenta complexos de Gd(III) e quarenta e dois complexos de $\mathrm{Tb}(\mathrm{III})$; todos a partir de estruturas cristalográficas de alta qualidade, com fator $\mathrm{R}<5 \%$. Os erros médios absolutos, obtidos com o modelo Sparkle/PM3, considerando todas as distâncias interatômicas do tipo lantanídeo-átomo ligante, foram 0,080 ̊ para Eu(III), 0,063 $\AA$ para Gd(III) e 0,070 ̊ para Tb(III). Estes valores médios são similares aos obtidos com o modelo Sparkle/AM1 $(0,082 \AA$, 0,061 $\mathrm{A}$, e $0,068 \AA$, respectivamente). Além disso, a exatidão em reproduzir o poliedro de coordenação de complexos de $\mathrm{Eu}(\mathrm{III}), \mathrm{Gd}(\mathrm{III})$ e $\mathrm{Tb}(\mathrm{III})$ é similar à obtida utilizando métodos ab initio com potenciais efetivos de caroço. Finalmente, com o objetivo de avaliar se as geometrias preditas com o modelo Sparkle/PM3 são confiáveis, escolhemos um dos complexos de Eu(III), BAFZEO, para o qual geramos centenas de diferentes geometrias iniciais, onde variamos de forma aleatória as distâncias e ângulos entre os ligantes e o íon Eu(III). Em seguida, todas essas geometrias iniciais foram otimizadas usando o modelo Sparkle/PM3. Como resultado, observamos uma tendência significativa onde a geometria que apresentou o menor erro médio absoluto apresentou também a energia total mais baixa, o que reforça a validade do modelo Sparkle.

The Sparkle/PM3 model is extended to europium(III), gadolinium(III), and terbium(III) complexes. The validation procedure was carried out using only high quality crystallographic structures, for a total of ninety-six Eu(III) complexes, seventy Gd(III) complexes, and forty-two $\mathrm{Tb}$ (III) complexes. The Sparkle/PM3 unsigned mean error, for all interatomic distances between the trivalent lanthanide ion and the ligand atoms of the first sphere of coordination, is: $0.080 \AA$ for Eu(III); $0.063 \AA$ for $\mathrm{Gd}(\mathrm{III})$; and $0.070 \AA$ for $\mathrm{Tb}(\mathrm{III})$. These figures are similar to the Sparkle/AM1 ones of $0.082 \AA, 0.061 \AA$, and $0.068 \AA$ respectively, indicating they are all comparable parameterizations. Moreover, their accuracy is similar to what can be obtained by present-day $a b$ initio effective core potential full geometry optimization calculations on such lanthanide complexes. Finally, we report a preliminary attempt to show that Sparkle/PM3 geometry predictions are reliable. For one of the $\mathrm{Eu}(\mathrm{III})$ complexes, BAFZEO, we created hundreds of different input geometries by randomly varying the distances and angles of the ligands to the central $\mathrm{Eu}$ (III) ion, which were all subsequently fully optimized. A significant trend was unveiled, indicating that more accurate local minima geometries cluster at lower total energies, thus reinforcing the validity of sparkle model calculations.

Keywords: Sparkle model, AM1, PM3, lanthanide complexes, rare earth coordination compounds

\section{Introduction}

Lanthanide complexes of the trivalent ions of europium, gadolinium, and terbium display a wide range of

\footnotetext{
*e-mail: simas@ufpe.br
}

applications, with newer ones appearing in increasing numbers. ${ }^{1-11}$ More specifically, europium and terbium complexes exhibit luminescence and are thus mostly used as luminescent or phosphorescent sensors or probes. On the other hand, complexes of gadolinium are mainly used as magnetic resonance imaging contrast agents. 
The theoretical design of new ligands, capable of forming stable and highly luminescent complexes, where the aim is to achieve strong ligand to-metal energy transfer rates and intense metal-centered emission, requires a description of ligand field effects. Accordingly, characterization of the interaction between the ligands and the central ion can be done through the ligand field parameters, which can be calculated provided that the coordination polyhedron geometry of the complex is known. Within the simple overlap model, ${ }^{12,13}$ the values of ligand field parameters depend mainly on the interatomic distances between the ligand atoms and the central lanthanide ion. This dependence goes with the third, the fifth, and even with the seventh power of the lanthanide-ligand interatomic distances, thus amplifying any inaccuracies.

On the other hand, gadolinium complexes which serve as magnetic resonance imaging contrast agents normally contain one coordinated inner-sphere water molecule. Because this water molecule is in fast exchange with bulk solvent, the gadolinium ion is able to catalytically change the relaxation rate of solvent protons, a phenomenon called relaxivity. A larger relaxivity means either that imaging can be carried out in low concentration target regions, or that the contrast agent may be administered at a lower dose. For the inner-sphere water molecule, the relaxation occurs predominantly via the dipolar mechanism, which has a $1 / \mathrm{r}^{6}$ dependence where $r$ is the distance of the gadolinium ion to the water proton. ${ }^{14}$

Hence, the geometry of a lanthanide complex is its single most relevant feature for complex design. Even more important is an accurate knowledge of the distances between the lanthanide ion and its directly coordinated ligand atoms. This knowledge is essential for a correct assessment of the influence of the chemical environment on the $4 \mathrm{f}^{\mathrm{n}}$ lanthanide ion configuration and of its effect on the spectroscopic and magnetic properties of the complex.

However, modeling lanthanide complexes is a challenging task because lanthanide ions do not display stereochemical preferences, possess a handful of high coordination numbers, and display small energy variations among their various coordination polyhedron geometries.

In a recent paper we introduced Sparkle/AM1 $1{ }^{15}$ a new paradigm for semiempirical quantum chemical calculations on lanthanide complexes. In this model, when a lanthanide complex is calculated, the lanthanide is represented by a sparkle, whereas the ligands are modeled by AM1. ${ }^{16}$ Besides the geometry, this allows the calculation of many other properties of the complexes, such as vibrational spectra, thermodynamic quantities, isotopic substitution effects and force constants, ionization potential, electron densities, dipole moments, etc. ${ }^{17}$
The Sparkle/AM1 ${ }^{18-24}$ was mainly designed to predict the ground state geometries of lanthanide complexes at a level of accuracy useful for complex design. Recent research on lanthanide complexes has in fact indicated that Sparkle/AM1 coordination polyhedron geometries are comparable to, if not better than geometries obtained from the best contemporary ab-initio full geometry optimization calculations with effective core potentials. ${ }^{25,26}$ Besides, Sparkle/AM1 calculations are hundreds of times faster, ${ }^{15}$ and have been recently employed for the study of quantum yields of luminescence. ${ }^{27-34}$

However, although AM1 generally produces satisfactory results and its trustworthiness has been extensively timetested, other semiempirical models may prove more advantageous for some particular applications.

$\mathrm{PM}^{35,36}$ is also a very popular semiempirical molecular orbital model, which predominantly gives enthalpies of formation with lower average errors than AM1. Indeed, PM3 has a wide following and is available in a variety of quantum chemical softwares, both commercial and non-commercial. ${ }^{17,37-45}$ Recently, for example, PM3 has been used by Lu et al. ${ }^{46}$ to calculate molecular orbital properties of the ligands of lanthanide (III) double decker complexes, which were helpful to the understanding of the electrochemical properties of the complexes. Possibly, researchers in general will be able to gain more insights, as PM3 parameters for the lanthanides become available, because PM3 calculations will then become possible, not only for the ligands, but for the whole complexes as well.

In order to amplify the range of applications of our sparkle model, we advance, in the present article, Sparkle/PM3 parameters for the calculation of $\mathrm{Eu}(\mathrm{III}), \mathrm{Gd}(\mathrm{III})$, and $\mathrm{Tb}$ (III) complexes to complement the Sparkle/AM1 parameters that have already been published for these ions..$^{15}$ We also present some evidence that geometries obtained via Sparkle/PM3 calculations are indeed trustworthy.

\section{Results and Discussion}

The Sparkle model assumes that the angular effects of the $f$ orbitals are negligible, and do not take them into account. The sparkle model replaces the lanthanide(III) ion by a Coulombic charge of $+3 e$ superimposed to a repulsive exponential

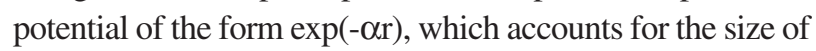
the ion; provides three electrons to the orbitals of the ligands; adds two Gaussian functions to the core-core repulsion energy term; and includes the lanthanide atomic mass. Thus, the sparkle model assumes that the lanthanide trications behave like simple ions, without any angular steric properties.

The parameterization procedure used to obtain the Sparkle/PM3 parameters for $\mathrm{Eu}(\mathrm{III}), \mathrm{Gd}(\mathrm{III})$, and $\mathrm{Tb}(\mathrm{III})$ 
was essentially the same as the one of our previous work..$^{15}$ Accordingly, we only used high quality crystallographic structures (R-factor $<5 \%$ ) of complexes taken from the Cambridge Structural Database 2003 (CSD), ${ }^{47-49}$ having found a total of 96 structures of complexes of $\mathrm{Eu}(\mathrm{III}), 70 \mathrm{of}$ $\mathrm{Gd}(\mathrm{III})$, and 42 of $\mathrm{Tb}(\mathrm{III})$. As training sets we used the same three subsets of 15 complexes each, already chosen for the parameterization of Sparkle/AM1 for the same ions. ${ }^{15}$

The Sparkle/PM3 parameters found for the three lanthanide ions are shown in Table 1.

Table 1. Parameters for the Sparkle/PM3 model for the Eu(III), Gd(III) and $\mathrm{Tb}(\mathrm{III})$ ions

\begin{tabular}{lccc}
\hline & \multicolumn{3}{c}{ Sparkle/PM3 } \\
\hline GSS & Eu(III) & Gd(III) & Tb(III) \\
ALP & 2.5863246694 & 54.8086404668 & 56.2564137683 \\
$\mathrm{a}_{1}$ & 0.6101627168 & 0.7706615984 & 1.3428294115 \\
$\mathrm{~b}_{1}$ & 7.1373146362 & 7.5453068267 & 7.5782265384 \\
$\mathrm{c}_{1}$ & 1.7807085112 & 1.7636673188 & 1.7181508908 \\
$\mathrm{a}_{2}$ & 0.3415714636 & 0.0936188340 & 0.2651000290 \\
$\mathrm{~b}_{2}$ & 9.1732778046 & 8.2224517067 & 6.4476118233 \\
$\mathrm{c}_{2}$ & 3.0121099267 & 2.9879390071 & 2.9952711306 \\
${ }^{*}$ EHEAT / & 1006.6 & 991.37 & 999.0 \\
$\left(\mathrm{kcal} \mathrm{mol}{ }^{-1}\right)$ & 151.9650 & 157.2500 & 158.92534 \\
AMS / amu & & & \\
\hline
\end{tabular}

* The heat of formation of the Eu(III), Gd(III) and Tb(III) ions in Sparkle/PM3 and Sparkle/AM1 models were obtained by adding to the heat of atomization of each respective lanthanide, their first three ionization potentials.

As geometry accuracy measures, we used the average unsigned mean error for each complex $i, U M E_{i}$, defined as:

$U M E_{i}=\frac{1}{n_{i}} \sum_{j=1}^{n_{i}}\left|R_{i, j}^{C S D}-R_{i, j}^{\text {calc }}\right|$ where $n_{i}$ is the number of ligand atoms directly coordinating the lanthanide ion. Two cases have been examined: $(i)$ $\mathrm{UME}_{(\mathrm{Ln}-\mathrm{L})} \mathrm{s}$ involving the interatomic distances $R_{j}$ between the lanthanide central ion, Ln, and the atoms of the coordination polyhedron, $\mathrm{L}$, important to complex design; and (ii) UMEs of all the edges of the pyramids, that is, of the interatomic distances $R_{j}$ between the lanthanide central ion and the atoms of the coordination polyhedron, as well as all the interatomic distances $R_{j}$ between all atoms of the coordination polyhedron. Tables S1, S2, and S3 of the supplementary material present the $\mathrm{UME}_{(\mathrm{Ln}-\mathrm{L})} \mathrm{S}$ and UMEs for both Sparkle/PM3 and Sparkle/AM1 for Eu(III), $\mathrm{Gd}(\mathrm{III})$, and $\mathrm{Tb}(\mathrm{III})$, respectively.

Table 2 presents the unsigned mean errors for both Sparkle/PM3 and Sparkle/AM1 for various types of distances in the $\mathrm{Eu}(\mathrm{III}), \mathrm{Gd}(\mathrm{III})$ and $\mathrm{Tb}(\mathrm{III})$ complexes considered. Results indicate that, for the three lanthanide ions considered, the two models are essentially equivalent. Distances between the lanthanide ion and its directly coordinated ligand atoms are predicted with higher accuracy than either the distances between two lanthanide ions in dilanthanide compounds, or the distances between atoms of the faces of the coordination polyhedron. This is fortunate, because radial lanthanide ion-ligand atom distances are far more important for both luminescent complex design ${ }^{32,33,50}$ and magnetic resonance imaging contrast agent design. ${ }^{14}$

Assuming that the sparkle model is a good representation of the lanthanide ion, as well as of its interactions with the ligands, the distribution of these UMEs should be random around a mean, whose value can be used as a measure of accuracy of the model. Since the UMEs are positive, defined in the domain $(0, \infty)$, they should follow the gamma distribution which has the probability density function $\mathrm{g}(x ; \mathrm{k}, \theta)$, where $x>0$ stands for the UMEs, $\mathrm{k}>0$ is the

Table 2. Sparkle/PM3 and Sparkle/AM1 unsigned mean errors for all distances involving the central lanthanide ion, Ln, and the ligand atoms of the coordination polyhedron, L, for ninety-six Eu(III) complexes; seventy Gd(III) complexes and forty-two Tb(III) complexes considered

\begin{tabular}{|c|c|c|c|c|c|c|}
\hline \multirow{2}{*}{ Model } & \multicolumn{6}{|c|}{ Unsigned mean errors for specific types of distances / $\AA$} \\
\hline & Ln-Ln & Ln-O & Ln-N & L-L' & Ln-L and Ln-Ln & Ln-L, Ln-Ln and L-L' \\
\hline \multicolumn{7}{|l|}{ Europium (III) } \\
\hline Sparkle/PM3 & 0.212 & 0.098 & 0.056 & 0.183 & 0.080 & 0.161 \\
\hline Sparkle/AM1 & 0.162 & 0.085 & 0.088 & 0.217 & 0.082 & 0.183 \\
\hline \multicolumn{7}{|c|}{ Gadolinium (III) } \\
\hline Sparkle/PM3 & 0.213 & 0.057 & 0.085 & 0.154 & 0.063 & 0.132 \\
\hline Sparkle/AM1 & 0.183 & 0.060 & 0.074 & 0.021 & 0.061 & 0.166 \\
\hline \multicolumn{7}{|l|}{ Terbium(III) } \\
\hline Sparkle/PM3 & 0.208 & 0.071 & 0.059 & 0.175 & 0.070 & 0.155 \\
\hline Sparkle/AM1 & 0.225 & 0.075 & 0.044 & 0.212 & 0.068 & 0.172 \\
\hline
\end{tabular}


shape parameter, and $\theta>0$ is the scale parameter of the gamma distribution. The expected value of the gamma distribution is simply $\mathrm{k} \theta$. The shape and scale parameters were estimated with the method of maximum likelihood in order to obtain the gamma distribution fit of the UME data.

The quality of the gamma distribution fit can be assessed via the one-sample non-parametric Kolmogorov-Smirnov ${ }^{51}$ test. For the hypothesis that the UME values follow a gamma distribution not to be rejected at the usual level of $5 \%$, the p-value of the test statistic must thus be larger than 0.05 . And the higher the p-value, whose maximum possible value is 1 , the higher the probability that the UMEs deviations of the mean are random, and the more justifiable is the use of the statistical tools employed here, and, by extension, of the sparkle model itself.

(a)

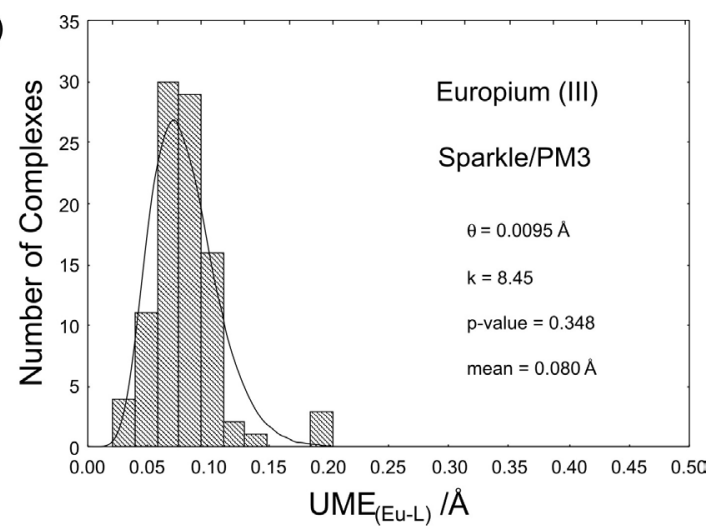

(b)

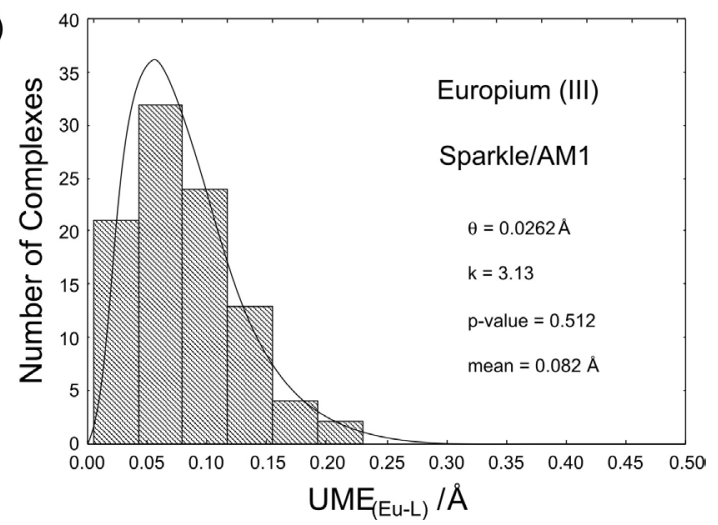

Figure 1. Probability densities of the Gamma distribution fits of the $\mathrm{UME}_{(\mathrm{Ln}-\mathrm{L})} \mathrm{s}$ for the Eu(III) Sparkle/PM3 and Sparkle/AM1 models, superimposed to histograms of the same data for all $96 \mathrm{Eu}$ (III) complexes considered; where $\mathrm{k}$ is the shape parameter and $\theta$ is the scale parameter of the gamma distribution; the p-value is a measure of the significance of the gamma distribution fit; and mean is the expected value of the fitted gamma distribution, which is set to be equal to the arithmetic mean value of the $96 \mathrm{UME}_{(\mathrm{Ln}-\mathrm{L})}$ s.

Figure 1 presents a gamma distribution fit of the $\mathrm{UME}_{(\mathrm{Eu}-\mathrm{L})}$ s for europium(III) for both Sparkle/PM3 and the already published Sparkle/AM1. ${ }^{15}$ Superimposed to the fit, a histogram of the data with the number of bars

chosen to best adjust the histogram to the curve obtained from the gamma distribution fit is also presented so that the reader can check the regions where the actual UMEs really occurred. The p-value of the gamma distribution fits for Sparkle/PM3 and Sparkle/AM1 are 0.348 and 0.512, respectively, both above the 0.05 value, thus attaching statistical significance to the fit and, by extension, to both sparkle models as well. Figures 2 and 3 present similar results for the sparkle models of gadolinium(III) and terbium(III), with similar results and conclusions.

(a)

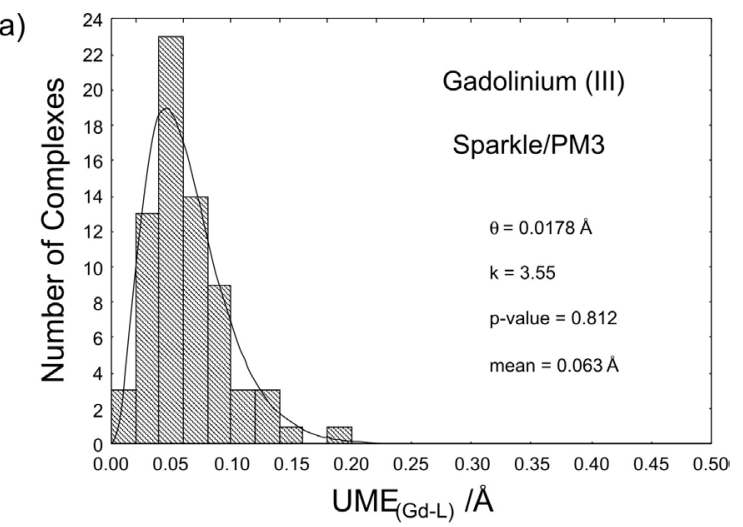

(b)

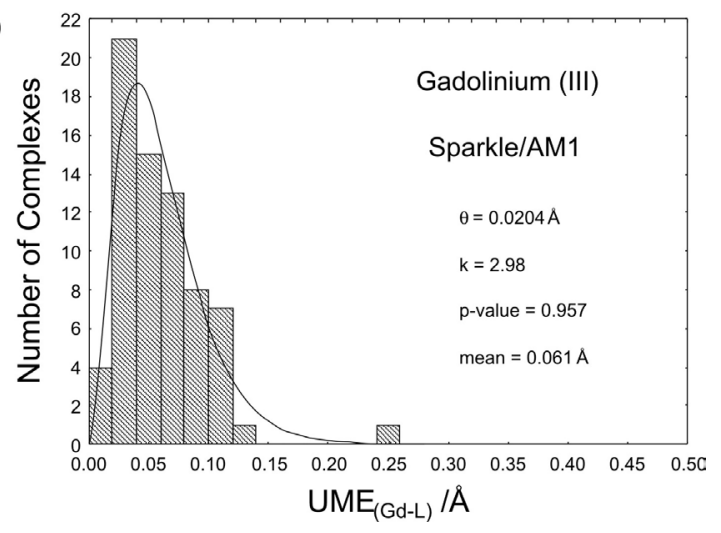

Figure 2. Probability densities of the Gamma distribution fits of the $\mathrm{UME}_{(\mathrm{Ln}-\mathrm{L})} \mathrm{s}$ for the Gd(III) Sparkle/PM3 and Sparkle/AM1 models, superimposed to histograms of the same data for all $70 \mathrm{Gd}(\mathrm{III})$ complexes considered; where $\mathrm{k}$ is the shape parameter and $\theta$ is the scale parameter of the gamma distribution; the p-value is a measure of the significance of the gamma distribution fit; and mean is the expected value of the fitted gamma distribution, which is set to be equal to the arithmetic mean value of the $70 \mathrm{UME}_{(\mathrm{Ln}-\mathrm{L})} \mathrm{s}$.

When a complex, whose experimental geometry is unknown, is subject to a Sparkle/PM3 calculation, an input geometry must be provided by the user. Since lanthanide complexes are flexible, the conformational energy hypersurface of such complex may contain a number of local minima, and by definition, one global minimum. Thus, the input geometry may either converge to one of the local minima, or ideally, to the global minimum. For the sparkle model to be useful, the minima with lower energies 
(a)

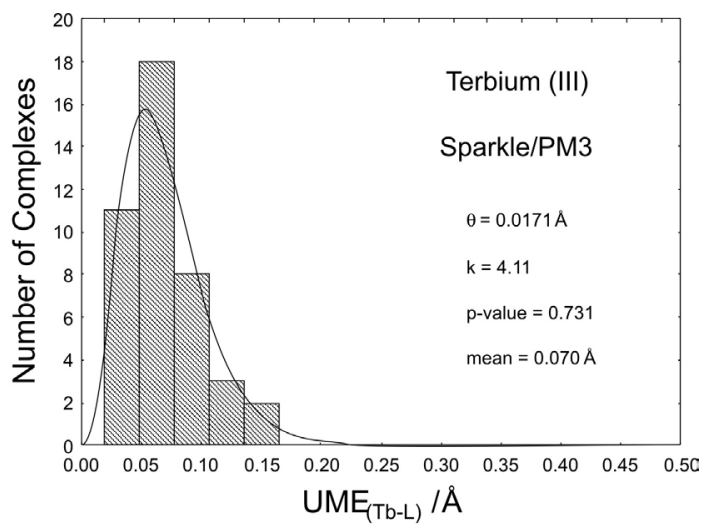

(b)

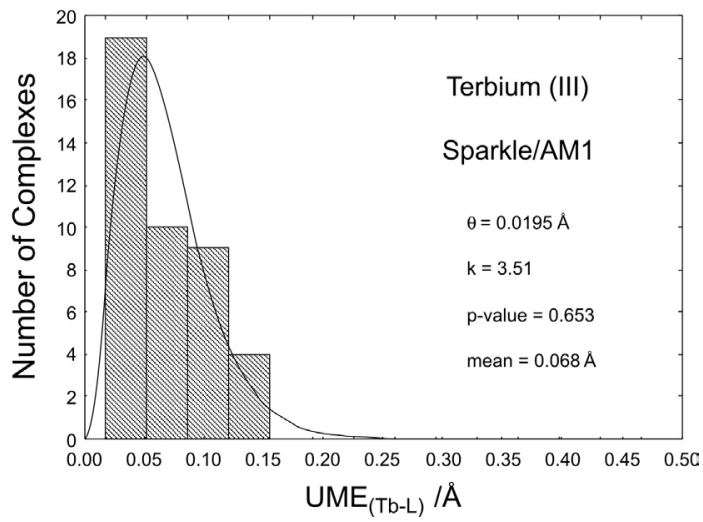

Figure 3. Probability densities of the Gamma distribution fits of the $\mathrm{UME}_{(\mathrm{Ln}-\mathrm{L})} \mathrm{s}$ for the $\mathrm{Tb}(\mathrm{III})$ Sparkle/PM3 and Sparkle/AM1 models, superimposed to histograms of the same data for all $42 \mathrm{~Tb}$ (III) complexes considered; where $\mathrm{k}$ is the shape parameter and $\theta$ is the scale parameter of the gamma distribution; the p-value is a measure of the significance of the gamma distribution fit; and mean is the expected value of the fitted gamma distribution, which is set to be equal to the arithmetic mean value of the $42 \mathrm{UME}_{(\mathrm{Ln}-\mathrm{L})}$ s.

must also be the ones closer to the experimental geometry. Likewise, as the energies of the local minima increase, we expect their $\mathrm{UME}_{(\mathrm{Ln}-\mathrm{L})}$ s to also increase.

In order to verify this hypothesis, a particular europium(III) complex, of CSD code BAFZEO, was selected as a case study. BAFZEO was chosen because: (i) it is flexible; (ii) it is coordinated to four ligands of three different types: two nitrates, one $\beta$-diketone and one terpyridine; and (iii) a full Sparkle/PM3 optimization of its geometry is relatively fast.

We then generated 200 different input geometries for this complex. Each of the geometries resulted from the application of a procedure to each and every one of its ligands in an independent manner. In this procedure, the ligands are considered to be rigid and independent of each other and of the central europium ion. Starting with the experimental geometry, for each ligand we proceeded as follows: $(i)$ we defined a randomly oriented Cartesian coordinate system whose origin is located at the center of mass of the ligand; (ii) we then randomly chose one of the three axis of this Cartesian coordinate system; (iii) we rotated the ligand around this chosen axis by a random angle in the interval $\left[+30^{\circ},-30^{\circ}\right] ;(i v)$ subsequently, one of the atoms of the ligand, we called atom R, was randomly chosen to define the axis connecting it to the europium ion; $(v)$ a random translation, in the direction of this axis, was finally applied to the whole ligand, the magnitude of this translation in the interval $[-15 \%,+15 \%]$ of the interatomic distance between the europium ion and atom $\mathrm{R}$ of the ligand.

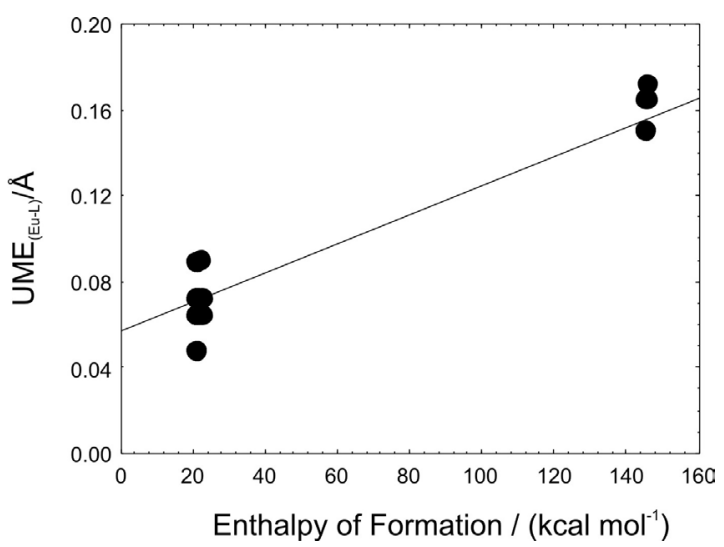

Figure 4. Clusters of output geometries obtained from Sparkle/PM3 full geometry optimizations of random input geometries for the europium complex of CSD code BAFZEO, showing that the group of clusters with the highest enthalpies of formation was also the group of clusters with the highest $\mathrm{UME}_{(\mathrm{Eu}-\mathrm{L})} \mathrm{s}$. The number of optimized geometries comprising each group of clusters is also shown. The trendline is present just to guide the eye.

For each of the 200 different input geometries, we performed a full Sparkle/PM3 geometry optimization. For some of the input geometries, the starting distances of the originally coordinating atoms were so far away from the europium atom that the corresponding Sparkle/PM3 geometry optimizations converged to uncoordinated complexes. A total of 64 of the outputs were then discarded for this reason. The remaining 136 output geometries with properly coordinated ligands grouped themselves into two main clusters of local minima, as can be seen in Figure 4: one around an enthalpy of formation of $143 \mathrm{kcal} \mathrm{mol}^{-1}$, with 10 outputs, and the other around $22 \mathrm{kcal} \mathrm{mol}^{-1}$, with 126 outputs. As expected, the cluster with the highest enthalpies of formation was also the cluster with the highest $\mathrm{UME}_{(\mathrm{Eu}-\mathrm{L})}$ and this is precisely the trend we were expecting. Nevertheless, we then decided to examine in greater detail the cluster around $22 \mathrm{kcal} \mathrm{mol}^{-1}$. Figure 5 shows that this cluster is actually comprised of seven different smaller clusters of local minima, all very similar and with very low $\mathrm{UME}_{(\mathrm{Eu}-\mathrm{L})} \mathrm{S}$ around $0.07 \AA$, a level of accuracy already useful for complex design. The number of outputs in each of the smaller clusters is also indicated in Figure 5. The cluster with the lowest enthalpy of formation, at $21.2 \mathrm{kcal} \mathrm{mol}^{-1}$, happened to be 
also the cluster with the lowest $\mathrm{UME}_{(\mathrm{Eu}-\mathrm{L})} \mathrm{s}$ at $0.048 \AA$. As shown in Figure 5, seven different inputs converged to this minimum, which likely is also the global minimum.

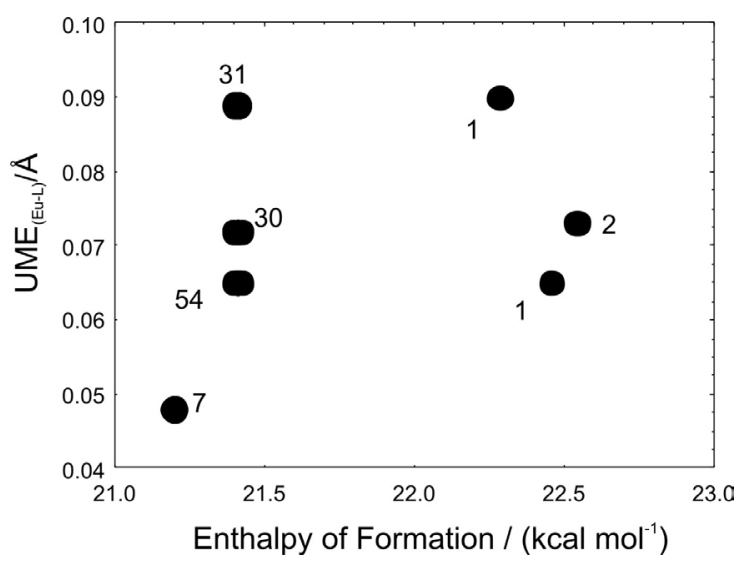

Figure 5. Enlargement of the group of clusters of Figure 4 located around $22 \mathrm{kcal} \mathrm{mol}^{-1}$, showing the seven sub-clusters obtained, as well as the number of elements in each. The leftmost sub-cluster with the lowest enthalpy of formation, with 7 elements, happened to be also the cluster with the lowest $\mathrm{UME}_{(\mathrm{Eu}-\mathrm{L})}$ s. The elements are output geometries obtained from Sparkle/PM3 full geometry optimizations of random input geometries for the europium complex of CSD code BAFZEO.

These results indicate that a significant trend was unveiled by this study: that more accurate geometry local minima tend to cluster at lower total energies. This trend confirms the validity of Sparkle/PM3 as a trustworthy geometry prediction tool.

Recently, an exhaustive study by our research group has been accomplished on coordination polyhedron geometry prediction accuracies of $a b$ initio effective core potential ( $a b$ initio/ECP) calculations. ${ }^{26}$ The study consisted of complete full geometry optimization calculations on dozens of complexes of various lanthanide ions, the largest containing 164 atoms, varying both basis sets (STO-3G, 3-21G, 6-31G, 6-31G*, and 6-31+G) and method (HF, B3LYP, and MP2 full). The amazing conclusion was that RHF/STO-3G/ ECP appears to be the most efficient model chemistry in terms of coordination polyhedron crystallographic geometry predictions from isolated lanthanide complex ion calculations. Contrary to what would normally be expected, either an increase in the basis set or inclusion of electron correlation, or both, consistently enlarged the deviations and aggravated the quality of the predicted coordination polyhedron geometries.

For each of the $\mathrm{Eu}(\mathrm{III}), \mathrm{Gd}(\mathrm{III})$, and $\mathrm{Tb}(\mathrm{III})$ ions, the study reported $a b$-initio/ECP full geometry optimizations on six complexes. ${ }^{26}$

The RHF/STO-3G/ECP average UME and UME $\mathrm{UMn}_{(\mathrm{L})}$ for the six $\mathrm{Eu}(\mathrm{III})$ complexes calculated were $0.119 \AA$ $\AA$ and $0.042 \AA$, similar to the respective Sparkle/PM3 numbers of $0.154 \AA$ and $0.060 \AA$; and to the Sparkle/AM1 numbers of $0.122 \AA$ and $0.046 \AA$.

Likewise, the RHF/STO-3G/ECP average UME and $\mathrm{UME}_{(\mathrm{Ln}-\mathrm{L})}$ for the six $\mathrm{Gd}(\mathrm{III})$ complexes calculated were $0.116 \AA$ and $0.047 \AA$, also similar to the respective Sparkle/PM3 numbers of $0.096 \AA$ and $0.054 \AA$; and to the Sparkle/AM1 numbers of $0.100 \AA$ and $0.051 \AA$.

Finally, for the six $\mathrm{Tb}(\mathrm{III})$ complexes, the average UME and $\mathrm{UME}_{(\mathrm{Ln}-\mathrm{L})}$ for the RHF/STO-3G/ECP geometries were reported as $0.164 \AA$ and $0.048 \AA$; again, comparable to the respective Sparkle/PM3 numbers of $0.117 \AA$ and $0.049 \AA$; and to the Sparkle/AM1 numbers of $0.110 \AA$ and $0.043 \AA$.

\section{Conclusions}

The most accurate $a b$ initio full geometry optimization calculations that can be nowadays carried out on europium, gadolinium and terbium complexes, of a size large enough to be of relevance to present-day research, exhibit the same accuracy of either Sparkle/PM3 or Sparkle/AM1 models. Our results do indicate that the Sparkle model is an accurate and statistically valid tool for the prediction of coordination polyhedra of lanthanide complexes.

Given the fact that sparkle calculations are hundreds of times faster, potential energy surface scan searches for a global minimum become feasible. And from the results presented in this article, these searches appear to be indeed meaningful. Sparkle calculations can also be used in molecular dynamics when calculations on the same system must be carried out repeatedly.

More importantly, the ability to perform a screening on many different putative structures of lanthanide complexes in a combinatorial manner, made possible by both Sparkle/PM3 and Sparkle/AM1, may prove to be of importance for luminescence or magnetic resonance imaging research.

\section{Acknowledgments}

We appreciate the financial support from $\mathrm{CNPq}$, and also grants from the IM2C (Brazilian Millennium Institute on Complex Materials) and RENAMI (Brazilian Molecular and Interfaces Nanotechnology Network). The authors are grateful to Prof. A. E. Almeida Paixão for the use of Statistica 6.0. Finally, we gratefully acknowledge the Cambridge Crystallographic Data Centre for the Cambridge Structural Database.

\section{Supplementary Information}

Instructions on how to run lanthanide complexes Sparkle calculations with MOPAC 2007 (from http:// 
openmopac.net) and also on how to visualize the structures of the complexes using RASMOL (from http://www.umass. edu/microbio/rasmol/); sample MOPAC 2007 input (.mop) and output (.arc) files for the complex Eu[TREN-1,2$\mathrm{HOIQO}\left(\mathrm{H}_{2} \mathrm{O}\right)_{2}$. Tables of $\mathrm{UME}_{(\mathrm{Ln}-\mathrm{L})} \mathrm{s}$ and UMEs for both Sparkle/PM3 and Sparkle/AM1 for Eu(III), Gd(III), and $\mathrm{Tb}(\mathrm{III})$, respectively. Figures with gamma distribution fits of the UME data for both Sparkle/PM3 and Sparkle/AM1 models for $\mathrm{Eu}(\mathrm{III}), \mathrm{Gd}(\mathrm{III})$ and $\mathrm{Tb}(\mathrm{III})$. This material is available free of charge at http://jbcs.sbq.org.br, as PDF file.

\section{References}

1. Lenaerts, P.; Görller-Walrand, C.; Binnemans, K.; J. Lumin. 2006, 117, 163.

2. Kautenburger, R.; Nowotka, K.; Beck, H. P.; Anal. Bioanal. Chem. 2006, 384, 1416.

3. Tsuchiya, D.; Kunishima, N.; Kamiya, N.; Jingami, H.; Morikawa, K.; Proc. Natl. Acad. Sci. 2002, 99, 2660.

4. Buunzli, J.-C. G.; Piquet, C.; Chem. Rev. 2002, 102, 1897.

5. Tsukube, H.; Shinoda, S.; Chem. Rev. 2002, 102, 2389.

6. Parker, D.; Dickins, R. S.; Puschmann, H.; Crossland, C.; Howard, S. A. K.; Chem. Rev. 2002, 102, 1977.

7. Lei, K.; Liu, W.; Huang, X.; Wang, D.; Chem. Pharm. Bull. 2006, 54, 1150.

8. Viguier, R. F. H.; Hulme, A. N.; J. Am. Chem. Soc. 2006, 128, 11370.

9. Skripinets, Yu. V.; Egorova, A. V.; Ukrainets, I. V.; Antonovich, V. P.; J. Anal. Chem. 2006, 61, 44.

10. Tan, M.; Song, B.; Wang, G. N.; Yuan, J.; Free Radical Biol. Med. 2006, 40, 1644.

11. Liu, Y.; Zhang, N.; Chen, Y.; Chen, G.-S.; Bioorg. Med. Chem. 2006, 14, 6615 .

12. Malta, O. L.; Chem. Phys. Lett. 1982, 87, 27.

13. Malta, O. L.; Chem. Phys. Lett. 1982, 88, 353.

14. Caravan, P.; Astashkin, A. V.; Raitsimring, A. M.; Inorg. Chem. 2003, 42, 3972.

15. Freire, R. O.; Rocha, G. B.; Simas, A. M.; Inorg. Chem. 2005, 44, 3299.

16. Dewar, M. J. S.; Zoebish, E. G.; Healy, E. F.; Stewart, J. J. P.; J. Am. Chem. Soc. 1985, 107, 3902.

17. Stewart, J. J. P.; MOPAC93.00 Manual; Fujitsu Limited: Tokyo, 1993.

18. Costa Jr., N. B.; Freire, R. O.; Rocha, G. B.; Simas, A. M.; Polyhedron 2005, 24, 3046.

19. Freire, R. O.; Rocha, G. B.; Simas, A. M.; Chem. Phys. Lett. 2005, 411, 61

20. Costa Jr., N. B.; Freire, R. O.; Rocha, G. B.; Simas, A. M.; Inorg. Chem. Commun. 2005, 8, 831.

21. Freire, R. O.; Costa Jr., N. B.; Rocha, G. B.; Simas, A. M.; J. Chem. Theory Comput. 2006, 2, 64.
22. Freire, R. O.; Monte, E. V.; Rocha, G. B.; Simas, A. M.; J. Organomet. Chem. 2006, 691, 2584.

23. Freire, R. O.; Costa Jr., N. B.; Rocha, G. B.; Simas, A. M.; J. Phys. Chem. A 2006, 110, 5897.

24. Bastos, C. C.; Freire, R. O.; Rocha, G. B.; Simas, A. M.; J. Photochem. Photobiol., A 2006, 117, 225.

25. Freire, R. O.; Rocha, G. B.; Albuquerque, R. Q.; Simas, A. M.; J. Lumin. 2005, 111, 81.

26. Freire, R. O.; Rocha, G. B.; Simas, A. M.; J. Mol. Model. 2006, $12,373$.

27. Nobre, S. S.; Lima, P. P.; Mafra, L.; Sa Ferreira, R. A.; Freire, R. O.; Fu, L.; Pischel, U.; de Zea Bermudez, V.; Malta, O. L.; Carlos, L. D.; J. Phys. Chem. C 2007, 111, 3275.

28. de Mesquita, M. E.; Junior, S. A.; Oliveira, F. C.; Freire, R. O.; Júnior, N. B. C.; de Sá, G. F.; Inorg. Chem. Commun. 2002, 5, 292.

29. de Mesquita, M. E.; Junior, S. A.; Júnior, N. B. C.; Freire, R. O.; Silva, F. R. G.; de Sá, G. F.; J. Solid State Chem. 2003, 171, 183.

30. Faustino, W. M.; Malta, O. L.; Teotonio, E. E. S.; Brito, H. F.; Simas, A. M.; de Sa, G. F.; J. Phys. Chem. A 2006, 110, 2510.

31. de Mesquita, M. E.; Gonçalves e Silva, F. R.; Albuquerque, R. Q.; Freire, R. O.; da Conceição, E. C.; da Silva, J. E. C.; Júnior, N. B. C.; de Sá, G. F.; J. Alloys Comp. 2004, 366, 124.

32. Freire, R. O.; Gonçalves e Silva, F. R.; Rodrigues, M. O.; de Mesquita, M. E.; Junior, N. B. C. ; J. Mol. Model. 2005, 12, 16.

33. Freire, R. O.; Albuquerque, R. Q.; Alves Jr., S.; Rocha, G. B.; de Mesquita, M. E.; Chem. Phys. Lett. 2005, 405, 123.

34. Pavithran, R.; Reddy, M. L. P.; Junior, S. A.; Freire, R. O.; Rocha, G. B.; Lima, P. P.; Eur. J. Inorg. Chem. 2005, $20,4129$.

35. Stewart, J. J. P.; J. Comp. Chem. 1989, 10, 209.

36. Stewart, J. J. P.; J. Comp. Chem. 1989, 10, 221.

37. Frisch, M. J.; Trucks, G. W.; Schlegel, H. B.; Scuseria, G. E.; Robb, M. A.; Cheeseman, J. R.; Zakrzewski, V. G.; Montgomery, J. A. Jr.; Stratmann, R. E.; Burant, J. C.; Dapprich, S.; Millam, J. M.; Daniels, A. D.; Kudin, K. N.; Strain, M. C.; Farkas, O.; Tomasi, J.; Barone, V.; Cossi, M.; Cammi, R.; Mennucci, B.; Pomelli, C.; Adamo, C.; Clifford, S.; Ochterski, J.; Petersson, G. A.; Ayala, P. Y.; Cui, Q.; Morokuma, K.; Malick, D. K.; Rabuck, A. D.; Raghavachari, K.; Foresman, J. B.; Cioslowski, J.; Ortiz, J. V.; Stefanov, B. B.; Liu, G.; Liashenko, A.; Piskorz, P.; Komaromi, I.; Gomperts, R.; Martin, R. L.; Fox, D. J.; Keith, T.; Al-Laham, M. A.; Peng, C. Y.; Nanayakkara, A.; Gonzalez, C.; Challacombe, M.; Gill, P. M. W.; Johnson, B. G.; Chen, W.; Wong, M. W.; Andres, J. L.; Head-Gordon, M.; Replogle, E. S.; Pople, J. A.; Gaussian 98; revision A.7; Gaussian; Inc.: Pittsburgh; PA; 1998.

38. HyperChem(TM) Professional 7.51; Hypercube, Inc., $1115 \mathrm{NW}$ $4^{\text {th }}$ Street, Gainesville, Fl 32601, USA.

39. Spartan '04; Wavefunction, Inc., 18401 Von Karman Avenue, Suite 370 Irvine, CA 92612, USA. 
40. Case, D. A.; Darden, T. A.; Cheatham III, T. E.; Simmerling, C. L.; Wang, J.; Duke, R. E.; Luo, R.; Merz, K. M.; Wang, B.; Pearlman, D. A.; Crowley, M.; Brozell, S.; Tsui, V.; Gohlke, H.; Mongan, J.; Hornak, V.; Cui, G.; Beroza, P.; Schafmeister, C.; Caldwell, J. W.; Ross, W. S.; Kollman, P. A.; AMBER version 8; University of California San Francisco, 2004.

41. Field, M. J.; Albe, M.; Bret, C.; Proust-De Martin, F.; Thomas, A.; J. Comput. Chem. 2000, 21, 1088.

42. VAMP, version 8; Accelrys Corporate Headquarters: San Diego, USA, 2001.

43. Rowley, C.; Hassinen, T.; Ghemical for GNOME, version 1.00, University of Iowa: Iowa City, USA, 2002.

44. Jorgensen, W. L. In The Encyclopedia of Computational Chemistry; Schleyer, P. v. R., ed., John Wiley \& Sons Ltd.: Athens, USA, 1998, vol. 5, p. 3281.

45. AMPAC, version 8; Semichem Inc.: Shawnee, USA, 2004.
46. Lu, G.; Bai, M.; Li, R.; Zhang, X.; Ma, C.; Lo, P.-C.; Ng, D.K.P.; Jiang, J.; Eur. J. Inorg. Chem. 2006, 18, 3703.

47. Allen, F. H.; Acta Crystallogr., Sect. B: Struct. Sci. 2002, 58, 380.

48. Bruno, I. J.; Cole, J. C.; Edgington, P. R.; Kessler, M.; Macrae, C. F.; McCabe, P.; Pearson, J.; Taylor, R.; Acta Crystallogr, Sect. B: Struct. Sci. 2002, 58, 389.

49. Allen, F. H.; Motherwell, W. D. S.; Acta Crystallogr., Sect. B: Struct. Sci. 2002, 58, 407.

50. de Sá, G. F.; Malta, O. L.; Donega, C. D.; Simas, A. M.; Longo, R. L.; Santa-Cruz, P. A.; da Silva, E. F.; Coord. Chem. Rev. 2000, 196, 165.

51. Conover, W. J. In Practical Nonparametric Statistics; $3^{\text {rd }}$ ed., Wiley II, B.; John Wiley \& Sons: New York, USA, 1999, p. 428.

Received: September 8, 2008 Web Release Date: September 11, 2009 


\title{
Sparkle/PM3 for the Modeling of Europium(III), Gadolinium(III), and Terbium(III) Complexes
}

\author{
Ricardo O. Freire, ${ }^{a}$ Gerd B. Rocha ${ }^{b}$ and Alfredo M. Simas ${ }^{*, c}$ \\ ${ }^{a}$ Departamento de Química, CCET, Universidade Federal de Sergipe, 49000-100 São Cristóvão-SE, Brazil \\ ${ }^{b}$ Departamento de Química, CCEN, Universidade Federal da Paraíba, 58059-970 João Pessoa-PB, Brazil

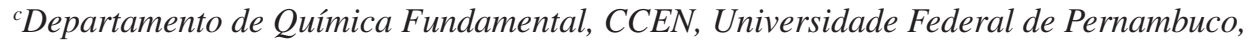 \\ 50590-470 Recife-PE, Brazil
}

\section{How to run lanthanide complexes Sparkle calculations with MOPAC2007}

Updated information on how to run the Sparkle Model can be found in http://www.sparkle.pro.br.

MOPAC2007 is a software released by Prof. James J. P. Stewart from Stewart Computational Chemistry of Colorado Springs, $\mathrm{CO}$, and represents a recent version of the MOPAC series of molecular modeling softwares, which started in 1981.

MOPAC2007 has Sparkle/AM1 and Sparkle/PM3 fully implemented.

A MOPAC2007 executable can be obtained from http://openmopac.net and is presently free for academics.

In order to be acquainted with the software, users are encouraged to read the MOPAC2007 manual at http://openmopac.net/manual/.

As the MOPAC2007 manual says:

"MOPAC is written with the non-theoretician in mind.

While MOPAC calls upon many concepts in quantum theory and thermodynamics and uses some fairly advanced mathematics, the users need not be familiar with these specialized topics."

At present, the most recent version of MOPAC2007 is 7.221 .

To run a Sparkle calculation in MOPAC 2007, proceed as follows:

i. Create a data-file with extension .mop which describes a molecular system and specifies the type of calculation that is to be carried out.

a. Use the lanthanide sparkles as you would use any atom in MOPAC.

b. For a Sparkle/AM1 calculation, use the keyword AM1 in the keyword line.

c. For a Sparkle/PM3 calculation, use the keyword PM3.

*e-mail: simas@ufpe.br ii. Command MOPAC to run the calculation using that data-file.

iii. Get the desired output on the system from the output files created by MOPAC.

Attention: Sparkles are overall neutral species

Please notice that when one uses a lanthanide as an element symbol in MOPAC2007, one is actually introducing an "overall neutral species" in the calculation, that is: $a+3$ charged sparkle plus three electrons which will be donated to the molecular orbitals of the organic part of the complex. If the whole complex is charged, then this must be indicated with the appropriate CHARGE keyword.

\section{MOPAC2007 Input (.mop) and output (.arc) files}

Sample input and output files can be found in http://www.sparkle.pro.br.

As an example, we are providing in the appendix of this supplementary material the content of a MOPAC2007 input and the corresponding output file for [Eu(TREN-1,2HOIQO $\left.)\left(\mathrm{H}_{2} \mathrm{O}\right)_{2}\right]$.

In order to reproduce the calculation, please obtain MOPAC2007.exe from http://openmopac.net, which is presently free for academics, copy the contents below to a text file, name it Eu_tren.mop, and simply open it with MOPAC2007.

Warning: MOPAC2007 output files with extension .arc may be confused with some types of compressed files in some Windows systems. Be sure to open them with notepad, or a similar text editor.

\section{How to visualize the input (.mop) structures with RASMOL}

Molecular and complex structures, as *.mop files, can be visualized with RASMOL 
(http://www.umass.edu/microbio/rasmol/getras.htm). The present version is 2.6 .

(1) In RASMOL, click File, then, Open;

(2) In the "Select Molecular Coordinate File", tell RASMOL to list all files of the type "MOPAC File Format";

(3) In "Look in" go to the proper folder and find your .mop file.

(2) The .mop file of interest now appears. Choose it and press $\mathrm{OK}$.
(3) The molecule or complex now appears drawn on the screen.

Warning: the bond connection algorithm of RASMOL may not work efficiently with some high coordination number lanthanide complexes. Some coordinating bonds may not appear, while sometimes some other spurious bond connections may also appear. However, the positions of the atoms are always correct.

\title{
4. Sample Input and Output Files
}

Begin of file Eu_tren.mop-

\author{
PM3 PRECISE NOINTER XYZ T=10D BFGS GNORM $=0.25+$ \\ NOLOG GEO-OK MMOK SCFCRT=1.D-10 \\ $\mathrm{Eu}(\mathrm{TREN}-1,2-\mathrm{HOIQO})(\mathrm{H} 2 \mathrm{O}) 2$
}

$\begin{array}{crrrrrr}\mathrm{Eu} & -6.005800 & 1 & -2.264900 & 1 & 0.222500 & 1 \\ \mathrm{O} & -3.918100 & 1 & -3.361800 & 1 & 0.580700 & 1 \\ \mathrm{O} & -5.770500 & 1 & -4.306300 & 1 & -0.928800 & 1 \\ \mathrm{O} & -4.373500 & 1 & -1.222500 & 1 & -1.126700 & 1 \\ \mathrm{O} & -4.928800 & 1 & -0.899200 & 1 & 1.827600 & 1 \\ \mathrm{O} & -8.352800 & 1 & -3.015400 & 1 & -0.206100 & 1 \\ \mathrm{O} & -6.871500 & 1 & -0.880100 & 1 & -1.515000 & 1 \\ \mathrm{O} & -7.473300 & 1 & -0.976500 & 1 & 1.561900 & 1 \\ \mathrm{O} & -6.467700 & 1 & -3.804500 & 1 & 2.032000 & 1 \\ \mathrm{C} & 0.000000 & 1 & 0.000000 & 1 & 0.000000 & 1 \\ \mathrm{H} & 0.969600 & 1 & 0.000000 & 1 & 0.000000 & 1 \\ \mathrm{H} & -0.297500 & 1 & 0.924500 & 1 & 0.000000 & 1 \\ \mathrm{C} & -0.500900 & 1 & -0.683000 & 1 & -1.260600 & 1 \\ \mathrm{H} & 0.030200 & 1 & -0.380500 & 1 & -2.013400 & 1 \\ \mathrm{H} & -0.367100 & 1 & -1.639900 & 1 & -1.172000 & 1 \\ \mathrm{C} & -2.337100 & 1 & 0.244100 & 1 & -2.575400 & 1 \\ \mathrm{C} & -3.799800 & 1 & 0.507000 & 1 & -2.702500 & 1 \\ \mathrm{C} & -4.248400 & 1 & 1.533000 & 1 & -3.476800 & 1 \\ \mathrm{H} & -3.630500 & 1 & 2.096200 & 1 & -3.882200 & 1 \\ \mathrm{C} & -5.628000 & 1 & 1.765700 & 1 & -3.681500 & 1 \\ \mathrm{C} & -6.107100 & 1 & 2.825200 & 1 & -4.478700 & 1 \\ \mathrm{H} & -5.506200 & 1 & 3.424100 & 1 & -4.860000 & 1 \\ \mathrm{C} & -7.439500 & 1 & 2.980700 & 1 & -4.692900 & 1 \\ \mathrm{H} & -7.745300 & 1 & 3.678000 & 1 & -5.223000 & 1 \\ \mathrm{C} & -8.330200 & 1 & 2.105600 & 1 & -4.127200 & 1 \\ \mathrm{H} & -9.236800 & 1 & 2.208700 & 1 & -4.306100 & 1 \\ \mathrm{C} & -7.922700 & 1 & 1.070000 & 1 & -3.291100 & 1 \\ \mathrm{H} & -8.542300 & 1 & 0.500500 & 1 & -2.896200 & 1 \\ \mathrm{C} & -6.564000 & 1 & 0.913800 & 1 & -3.063600 & 1 \\ \mathrm{C} & -6.104700 & 1 & -0.114100 & 1 & -2.187900 & 1 \\ \mathrm{C} & -0.460100 & 1 & 0.298900 & 1 & 2.329000 & 1 \\ \mathrm{H} & 0.363200 & 1 & 0.810700 & 1 & 2.275500 & 1 \\ \mathrm{H} & -0.448100 & 1 & -0.187800 & 1 & 3.166900 & 1 \\ \mathrm{C} & -1.605400 & 1 & 1.243700 & 1 & 2.343800 & 1 \\ \mathrm{H} & -1.436400 & 1 & 1.923800 & 1 & 3.014000 & 1\end{array}$




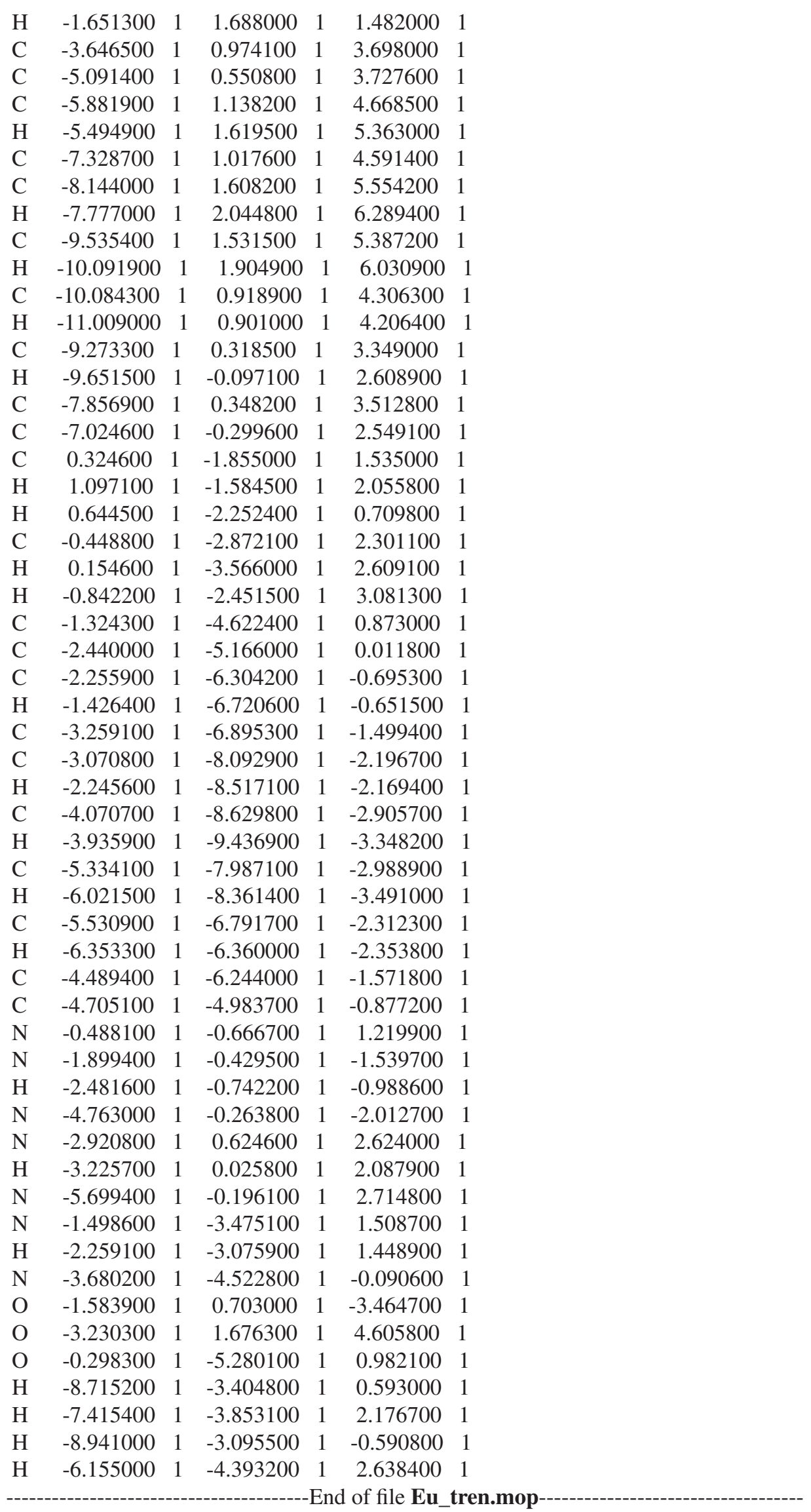




\section{SUMMARY OF PM3 CALCULATION}

MOPAC2007 (Version: 7.221W)

Fri Aug 29 01:18:10 2008

No. of days left $=197$

Empirical Formula: C36 H34 N7 O11 Eu

PM3 PRECISE NOINTER XYZ T=10D BFGS GNORM=0.25 + NOLOG GEO-OK MMOK SCFCRT=1.D-10

Eu(TREN-1,2-HOIQO)(H2O)2

PETERS TEST WAS SATISFIED IN BFGS OPTIMIZATION

SCF FIELD WAS ACHIEVED

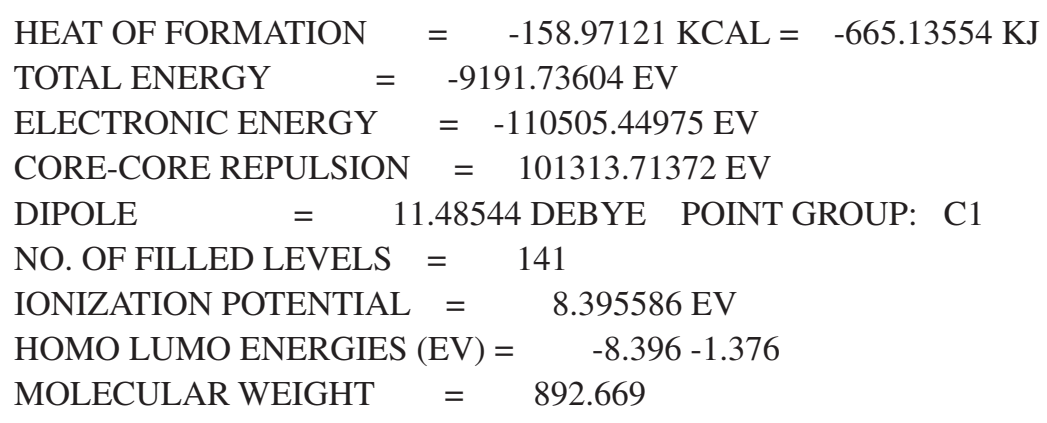

MOLECULAR DIMENSIONS (Angstroms)

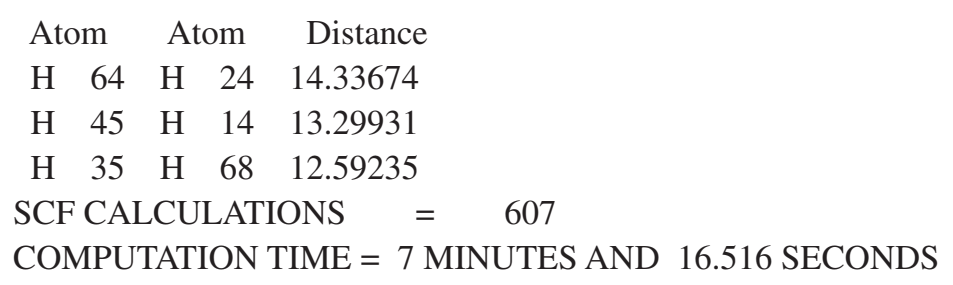

FINAL GEOMETRY OBTAINED

CHARGE

PM3 PRECISE NOINTER XYZ T=10D BFGS GNORM=0.25 + NOLOG GEO-OK MMOK SCFCRT=1.D-10

Eu(TREN-1,2-HOIQO)(H2O)2

$\begin{array}{ccccc}\mathrm{Eu} & -5.79105160+1 & -2.1803554+1 & 0.1786149+1 & 3.0000 \\ \mathrm{O} & -3.80291633+1 & -3.6210613+1 & 0.3854376+1 & -0.9267 \\ \mathrm{O} & -5.55156131+1 & -4.3789108+1 & -0.9268561+1 & -0.7876 \\ \mathrm{O} & -4.29148973+1 & -0.7735502+1 & -1.1823036+1 & -0.9220 \\ \mathrm{O} & -5.04919464+1 & -0.6520402+1 & 1.9727506+1 & -0.9060\end{array}$




\begin{tabular}{|c|c|c|c|c|}
\hline $\mathrm{O}$ & $-8.24126436+1$ & $-2.4420556+1$ & $0.0053056+1$ & -0.5949 \\
\hline U & $-6.55306600+1$ & $-0.6241143+1$ & $-1.5852553+1$ & -0.7908 \\
\hline 0 & $-7.25553901+1$ & $-1.2303536+1$ & $1.9360606+1$ & -0.8135 \\
\hline $\mathrm{O}$ & $-6.48088130+1$ & $-3.6145731+1$ & $2.0679390+1$ & -0.5971 \\
\hline $\mathrm{C}$ & $-0.12767246+1$ & $0.2461158+1$ & $0.1817746+1$ & -0.1127 \\
\hline $\mathrm{H}$ & $0.94803004+1$ & $0.5022839+1$ & $0.3026277+1$ & 0.0432 \\
\hline $\mathrm{H}$ & $-0.69115074+1$ & $1.1915494+1$ & $0.3521406+1$ & 0.0752 \\
\hline $\mathrm{C}$ & $-0.35576350+1$ & $-0.2775841+1$ & $-1.2397881+1$ & -0.0704 \\
\hline $\mathrm{H}$ & $0.31018550+1$ & $0.2682964+1$ & $-1.9383722+1$ & 0.0823 \\
\hline $\mathrm{H}$ & $-0.07245465+1$ & $-1.3540491+1$ & $-1.3054180+1$ & 0.0644 \\
\hline $\mathrm{C}$ & $-2.20353280+1$ & $0.8902581+1$ & $-2.4939535+1$ & 0.2978 \\
\hline $\mathrm{C}$ & $-3.67394025+1$ & $0.9483751+1$ & $-2.8130217+1$ & -0.2191 \\
\hline $\mathrm{C}$ & $-4.15490454+1$ & $1.8185968+1$ & $-3.7637863+1$ & -0.1043 \\
\hline $\mathrm{H}$ & $-3.45540481+1$ & $2.4680571+1$ & $-4.3079768+1$ & 0.1440 \\
\hline $\mathrm{C}$ & $-5.55036127+1$ & $1.9085218+1$ & $-4.0579169+1$ & -0.0112 \\
\hline $\mathrm{C}$ & $-6.02618669+1$ & $2.8086660+1$ & $-5.0429642+1$ & -0.0969 \\
\hline $\mathrm{H}$ & $-5.30612723+1$ & $3.4349844+1$ & $-5.5825192+1$ & 0.1142 \\
\hline $\mathrm{C}$ & $-7.37014326+1$ & 2.890 & $80+1$ & -0.0762 \\
\hline $\mathrm{H}$ & $-7.73778232+1$ & $3.5870809+1$ & $132+1$ & 0.1046 \\
\hline $\mathrm{C}$ & $-8.29388213+1$ & $2.0850033+1$ & $-4.6165323+1$ & -0.1174 \\
\hline $\mathrm{H}$ & $-9.36029191+1$ & $2.1690517+1$ & $-4.8501345+1$ & 0.1065 \\
\hline $\mathrm{C}$ & $-7.86069994+1$ & $76+1$ & $5+1$ & -0.0421 \\
\hline $\mathrm{H}$ & $-8.56370647+1$ & $0.5682022+1$ & $666+1$ & 0.1186 \\
\hline $\mathrm{C}$ & $-6.48304421+1$ & $1.1056813+1$ & $-3.3668466+1$ & -0.0967 \\
\hline $\mathrm{C}$ & $-5.96031269+1$ & $0.2062953+1$ & $-2.3770985+1$ & 0.2019 \\
\hline $\mathrm{C}$ & $-0.56676720+1$ & $-0.1075521+1$ & $393+1$ & -0.1011 \\
\hline $\mathrm{H}$ & $0.45320004+1$ & $0.2417213+1$ & $759+1$ & 0.0426 \\
\hline $\mathrm{H}$ & $-0.81939332+1$ & $-0.9249510+1$ & $3.3138916+1$ & 0.0744 \\
\hline $\mathrm{C}$ & $-1.53230865+1$ & $1.0700718+1$ & $56+1$ & -0.0736 \\
\hline $\mathrm{H}$ & $-1.20079485+1$ & $1.7007931+1$ & $35+1$ & 0.0828 \\
\hline $\mathrm{H}$ & $-1.49459952+1$ & $1.7193427+1$ & $62+1$ & 0.0602 \\
\hline $\mathrm{C}$ & $-3.79918767+1$ & $1.3496427+1$ & 3.788 & 0.2942 \\
\hline $\mathrm{C}$ & $-5.24733370+1$ & $51+1$ & 3.82 & -0.2529 \\
\hline $\mathrm{C}$ & $-6.11913698+1$ & $1.4940769+1$ & $4.7267842+1$ & -0.0608 \\
\hline $\mathrm{H}$ & $-5.74596391+1$ & $2.2340632+1$ & $5.4496933+1$ & 0.1482 \\
\hline $\mathrm{C}$ & $-7.50478083+1$ & $1.1498582+1$ & $4.7444442+1$ & -0.0285 \\
\hline $\mathrm{C}$ & $-8.38993343+1$ & $1.7395895+1$ & $5.6814596+1$ & -0.0835 \\
\hline $\mathrm{H}$ & $-7.99419799+1$ & $2.4648512+1$ & $6.4026384+1$ & 0.1179 \\
\hline $\mathrm{C}$ & $-9.72108914+1$ & $1.4051589+1$ & $5.6781387+1$ & -0.0766 \\
\hline $\mathrm{H}$ & $-10.40611343+1$ & $1.8613144+1$ & $6.4014877+1$ & 0.1100 \\
\hline $\mathrm{C}$ & $-10.22822753+1$ & $0.4740675+1$ & $4.7466032+1$ & -0.0957 \\
\hline $\mathrm{H}$ & $-11.29516861+1$ & $0.2270070+1$ & $4.7644520+1$ & 0.1103 \\
\hline $\mathrm{C}$ & $-9.39479595+1$ & $-0.1139890+1$ & $3.8279032+1$ & -0.0579 \\
\hline $\mathrm{H}$ & $-9.77139780+1$ & $-0.8365125+1$ & $3.0950307+1$ & 0.1140 \\
\hline $\mathrm{C}$ & $-8.02175785+1$ & $0.2173742+1$ & $3.8182106+1$ & -0.0752 \\
\hline $\mathrm{C}$ & $-7.08921583+1$ & $-0.3506500+1$ & $2.8959889+1$ & 0.1344 \\
\hline $\mathrm{C}$ & $0.29034151+1$ & $-1.9600737+1$ & $1.2134793+1$ & -0.1161 \\
\hline $\mathrm{H}$ & $1.32584149+1$ & $-1.7305667+1$ & $1.5488679+1$ & 0.0439 \\
\hline $\mathrm{H}$ & $0.37304138+1$ & $-2.2786473+1$ & $0.1488741+1$ & 0.0781 \\
\hline $\mathrm{C}$ & $-0.27214083+1$ & $-3.0919238+1$ & $2.0785880+1$ & -0.0688 \\
\hline & $0.54441247+1$ & $-3.7966511+1$ & $2.3347561+1$ & 0.0805 \\
\hline
\end{tabular}




$\begin{array}{lrrrr}\text { H } & -0.66128405+1 & -2.6869806+1 & 3.0414897+1 & 0.0619 \\ \mathrm{C} & -1.16368322+1 & -4.9650655+1 & 0.6490765+1 & 0.2997 \\ \mathrm{C} & -2.33681234+1 & -5.5213613+1 & -0.1134185+1 & -0.2196 \\ \mathrm{C} & -2.24399850+1 & -6.7277768+1 & -0.7673107+1 & -0.1044 \\ \mathrm{H} & -1.31215254+1 & -7.3068313+1 & -0.7082705+1 & 0.1438 \\ \mathrm{C} & -3.32876422+1 & -7.2450512+1 & -1.5411393+1 & -0.0113 \\ \mathrm{C} & -3.21634082+1 & -8.4931535+1 & -2.2009983+1 & -0.0982 \\ \mathrm{H} & -2.28545605+1 & -9.0639959+1 & -2.1036411+1 & 0.1141 \\ \mathrm{C} & -4.26059204+1 & -8.9741856+1 & -2.9524335+1 & -0.0749 \\ \mathrm{H} & -4.17317951+1 & -9.9392725+1 & -3.4631556+1 & 0.1048 \\ \mathrm{C} & -5.45448392+1 & -8.2362454+1 & -3.0798313+1 & -0.1168 \\ \mathrm{H} & -6.27157714+1 & -8.6396639+1 & -3.6869601+1 & 0.1075 \\ \mathrm{C} & -5.59153590+1 & -7.0223348+1 & -2.4502614+1 & -0.0407 \\ \mathrm{H} & -6.51154007+1 & -6.4332658+1 & -2.5402893+1 & 0.1215 \\ \mathrm{C} & -4.52990310+1 & -6.5156420+1 & -1.6714123+1 & -0.0981 \\ \mathrm{C} & -4.60695005+1 & -5.2575332+1 & -0.9822355+1 & 0.2084 \\ \mathrm{~N} & -0.55703136+1 & -0.7250202+1 & 1.2367767+1 & -0.0766 \\ \mathrm{~N} & -1.74854979+1 & -0.1750237+1 & -1.7065181+1 & -0.0537 \\ \mathrm{H} & -2.45407885+1 & -0.7234838+1 & -1.2272158+1 & 0.1615 \\ \mathrm{~N} & -4.59774584+1 & 0.1404652+1 & -2.1459825+1 & 0.6346 \\ \mathrm{~N} & -2.92435187+1 & 0.6303773+1 & 2.9716525+1 & -0.0392 \\ \mathrm{H} & -3.32466553+1 & -0.0488159+1 & 2.3367068+1 & 0.1566 \\ \mathrm{~N} & -5.76156696+1 & -0.0021041+1 & 2.9164812+1 & 0.7225 \\ \mathrm{~N} & -1.37898790+1 & -3.8348648+1 & 1.4533816+1 & -0.0596 \\ \mathrm{H} & -2.25043926+1 & -3.3387007+1 & 1.3076696+1 & 0.1579 \\ \mathrm{~N} & -3.54106413+1 & -4.8198177+1 & -0.2142965+1 & 0.6288 \\ \mathrm{O} & -1.41404762+1 & 1.7128994+1 & -2.9525342+1 & -0.4055 \\ \mathrm{O} & -3.39422074+1 & 2.2826708+1 & 4.4789702+1 & -0.4023 \\ \mathrm{O} & -0.06039046+1 & -5.5034025+1 & 0.6132755+1 & -0.4004 \\ \mathrm{H} & -8.37934540+1 & -1.8067675+1 & 0.7205355+1 & 0.2723 \\ \mathrm{H} & -6.95657616+1 & -2.8715894+1 & 2.4637501+1 & 0.2641 \\ \mathrm{H} & -9.08705670+1 & -2.6663940+1 & -0.3889297+1 & 0.2873 \\ \mathrm{H} & -6.52939585+1 & -4.3812505+1 & 2.6414903+1 & 0.2860\end{array}$




\begin{tabular}{|c|c|c|c|c|c|c|}
\hline $\mathrm{Eu}$ & 1.369000 & 1 & -1.681000 & 1 & 1.064000 & 1 \\
\hline $\mathrm{O}$ & -0.594000 & 1 & -1.511000 & 1 & 2.460000 & 1 \\
\hline $\mathrm{O}$ & 1.716000 & 1 & 0.317000 & 1 & 2.375000 & 1 \\
\hline O & 1.991000 & 1 & -2.567000 & 1 & -1.095000 & 1 \\
\hline $\mathrm{O}$ & 1.397000 & 1 & -4.078000 & 1 & 1.364000 & 1 \\
\hline $\mathrm{O}$ & 3.707000 & 1 & -2.249000 & 1 & 000 & 1 \\
\hline $\mathrm{O}$ & -0.576000 & 1 & -2.619000 & 1 & -0.275000 & 1 \\
\hline $\mathrm{O}$ & 1.734000 & 1 & -2.424000 & 1 & 3.467000 & 1 \\
\hline $\mathrm{O}$ & 0.000000 & 1 & 0.0 & 1 & 00 & 1 \\
\hline $\mathrm{O}$ & 2.951000 & 1 & 0.000000 & 1 & 000 & 1 \\
\hline $\mathrm{H}$ & 0.156000 & 1 & 0.883000 & 1 & 0.000000 & 1 \\
\hline $\mathrm{H}$ & -0.274000 & 1 & -0.199000 & 1 & -0.664000 & 1 \\
\hline $\mathrm{H}$ & 2.982000 & 1 & 0.80 & 1 & 0.1 & 1 \\
\hline $\mathrm{H}$ & 3.708000 & 1 & -0.126000 & 1 & -0.283000 & 1 \\
\hline $\mathrm{H}$ & -1.413000 & 1 & -1.268000 & 1 & 2.188000 & 1 \\
\hline $\mathrm{H}$ & -0.656000 & 1 & -2.048000 & 1 & 2.973000 & 1 \\
\hline $\mathrm{H}$ & 1.385000 & 1 & 0.473000 & 1 & 3.194000 & 1 \\
\hline $\mathrm{H}$ & 2.404000 & 1 & 0.600000 & 1 & 2.332000 & 1 \\
\hline $\mathrm{H}$ & 2.810000 & 1 & -2.538000 & 1 & -1.460000 & 1 \\
\hline $\mathrm{H}$ & 1.482000 & 1 & -2.464000 & 1 & -1.630000 & 1 \\
\hline $\mathrm{H}$ & 1.240000 & 1 & -4.690000 & 1 & 0.727000 & 1 \\
\hline $\mathrm{H}$ & 1.100000 & 1 & -4.312000 & 1 & 2.007000 & 1 \\
\hline $\mathrm{H}$ & 4.039000 & 1 & -2.947000 & 1 & 1.733000 & 1 \\
\hline $\mathrm{H}$ & 4.161000 & 1 & -1.664000 & 1 & 1.365000 & 1 \\
\hline $\mathrm{H}$ & -1.285000 & 1 & -2.255000 & 1 & -0.461000 & 1 \\
\hline $\mathrm{H}$ & -0.559000 & 1 & -3.190000 & 1 & -0.860000 & 1 \\
\hline $\mathrm{H}$ & 1.322000 & 1 & -2.194000 & 1 & 4.136000 & 1 \\
\hline $\mathrm{H}$ & 2.048000 & 1 & -3.130000 & 1 & 3.736000 & 1 \\
\hline
\end{tabular}


Begin of file Eu_9H2O.arc

SUMMARY OF PM3 CALCULATION

MOPAC2007 (Version: 7.221W)

Fri Sep 5 21:31:45 2008

No. of days left $=190$

Empirical Formula: H18 O9 Eu

PM3 PRECISE NOINTER XYZ BFGS T=10D GNORM=0.25 + NOLOG GEO-OK SCFCRT=1.D-10 CHARGE $=3$

cation nona-aqua-europium(III)

PETERS TEST WAS SATISFIED IN BFGS OPTIMIZATION

SCF FIELD WAS ACHIEVED

HEAT OF FORMATION $=323.51253 \mathrm{KCAL}=1353.57645 \mathrm{KJ}$

TOTAL ENERGY $\quad=\quad-2932.93411 \mathrm{EV}$

ELECTRONIC ENERGY $\quad=-14038.14466 \mathrm{EV}$

CORE-CORE REPULSION $=11105.21054 \mathrm{EV}$

DIPOLE $\quad=\quad 0.74707$ DEBYE POINT GROUP: $\mathrm{C} 1$

NO. OF FILLED LEVELS $=36$

CHARGE ON SYSTEM $=3$

IONIZATION POTENTIAL $=25.094038 \mathrm{EV}$

HOMO LUMO ENERGIES $($ EV $)=\quad-25.094-8.938$

MOLECULAR WEIGHT $\quad=\quad 314.101$

MOLECULAR DIMENSIONS (Angstroms)

\begin{tabular}{ccccc}
\multicolumn{2}{c}{ Atom } & \multicolumn{2}{c}{ Atom } & Distance \\
$\mathrm{H}$ & 21 & $\mathrm{H}$ & 17 & 6.27726 \\
$\mathrm{H}$ & 24 & $\mathrm{H}$ & 25 & 6.21230 \\
$\mathrm{H}$ & 19 & $\mathrm{H}$ & 27 & 6.06404
\end{tabular}

SCF CALCULATIONS = 627

COMPUTATION TIME $=15.094$ SECONDS

FINAL GEOMETRY OBTAINED

CHARGE

PM3 PRECISE NOINTER XYZ BFGS T=10D GNORM=0.25 +

NOLOG GEO-OK SCFCRT=1.D-10 CHARGE=3

cation nona-aqua-europium(III)

$\begin{array}{crrrr}\mathrm{Eu} & 1.40462264+1 & -1.5673041+1 & 1.0980307+1 & 3.0000 \\ \mathrm{O} & -0.62602985+1 & -1.6912689+1 & 2.5894117+1 & -0.6346 \\ \mathrm{O} & 1.28356344+1 & 0.5437862+1 & 2.4750130+1 & -0.6317 \\ \mathrm{O} & 1.91406739+1 & -1.9374370+1 & -1.2817347+1 & -0.6249 \\ \mathrm{O} & 1.07468252+1 & -4.0463089+1 & 1.4170107+1 & -0.6357 \\ \mathrm{O} & 3.65642145+1 & -2.7058871+1 & 1.0575400+1 & -0.6315 \\ \mathrm{O} & -0.64859859+1 & -2.3056741+1 & -0.1895231+1 & -0.6185 \\ \mathrm{O} & 2.23446691+1 & -2.0210425+1 & 3.4355211+1 & -0.6336\end{array}$




$\begin{array}{ccccc}\mathrm{O} & 0.13718823+1 & 0.1169164+1 & -0.1659702+1 & -0.6511 \\ \mathrm{O} & 3.21300067+1 & 0.0461864+1 & 0.4007516+1 & -0.6356 \\ \mathrm{H} & -0.08932428+1 & 0.9877652+1 & -0.5352742+1 & 0.3577 \\ \mathrm{H} & -0.54022369+1 & -0.5103638+1 & -0.4423260+1 & 0.2683 \\ \mathrm{H} & 3.32283437+1 & 0.9994108+1 & 0.6074852+1 & 0.3202 \\ \mathrm{H} & 4.01882657+1 & -0.0774508+1 & -0.1454768+1 & 0.3161 \\ \mathrm{H} & -1.12646602+1 & -0.9782210+1 & 3.0416101+1 & 0.3187 \\ \mathrm{H} & -1.13852200+1 & -2.4596997+1 & 2.9202422+1 & 0.3165 \\ \mathrm{H} & 0.81001136+1 & 1.3875800+1 & 2.3137292+1 & 0.3157 \\ \mathrm{H} & 1.70036605+1 & 0.7714119+1 & 3.3335148+1 & 0.3164 \\ \mathrm{H} & 2.16280332+1 & -2.4621982+1 & -2.0648355+1 & 0.3582 \\ \mathrm{H} & 1.90344393+1 & -1.0208535+1 & -1.5498264+1 & 0.2641 \\ \mathrm{H} & 0.62197075+1 & -4.7164519+1 & 0.8613262+1 & 0.3174 \\ \mathrm{H} & 1.36518858+1 & -4.6375883+1 & 2.1444770+1 & 0.3183 \\ \mathrm{H} & 3.89180005+1 & -3.6419587+1 & 0.8812133+1 & 0.3175 \\ \mathrm{H} & 4.56190747+1 & -2.3522460+1 & 1.1891585+1 & 0.3144 \\ \mathrm{H} & -1.57684495+1 & -2.4379757+1 & 0.1081006+1 & 0.3216 \\ \mathrm{H} & -0.73760631+1 & -2.6441853+1 & -1.1092130+1 & 0.3228 \\ \mathrm{H} & 1.78275142+1 & -1.9464584+1 & 4.3030049+1 & 0.3161 \\ \mathrm{H} & 3.10837346+1 & -2.3344788+1 & 3.7529159+1 & 0.3171\end{array}$

\section{Additional Tables and Figures}

The directly coordinating atoms of the ligands form the coordination polyhedron of the complex, whose faces are the polygonal bases of a set of adjacent pyramids that share the same apex, where the lanthanide ion is located. E a $\mathrm{ch} t \mathrm{w} o$ adjacent pyramids share one triangular face, and therefore, also one side of their polygonal bases.

The average unsigned mean error for each complex $i, U M E_{i}$, is defined as:

$$
U M E_{i}=\frac{1}{n_{i}} \sum_{j=1}^{n_{i}}\left|R_{i, j}^{C S D}-R_{i, j}^{\text {calc }}\right|
$$

where $n$ is the number of ligand atoms directly coordinating the lanthanide ion. Two cases have been examined: $(i) \mathrm{UME}_{(\mathrm{Ln}-\mathrm{L})} \mathrm{S}$ involving only the edges of the pyramidsthat have the apex as a vertice, that is, the interatomic distances $R_{j}$ between the lanthanide central ion, Ln, and the atoms of the coordination polyhedron, L, important to luminescent complex design; and (ii) UMEs of all the edges of the pyramids, that is, of the interatomic distances $R_{j}$ between the lanthanide central ion and the atoms of the coordination polyhedron, as well as all the interatomic distances $R_{j}$ between all atoms of the coordination polyhedron.

Tables S1, S2 and S3 show the Sparkle/PM3 and Sparkle/AM1 unsigned mean errors, UME ${ }_{(\mathrm{Ln}-\mathrm{L})} \mathrm{S}$ and UMEs, for the 96 structures containing Eu(III), 70 structures containing Gd(III) and the 42 structures containing $\mathrm{Tb}(\mathrm{III})$ respectively.

Figures S3 to S5 present, each, a gamma distribution fit of the respective UMEs for the present Sparkle/PM3 as well as for previously published Sparkle/AM1 models for europium, gadolinium and terbium. ${ }^{1}$ In all cases the respective p-values were above the critical value of 0.05 , ranging from 0.100 to 0.911 , thus validating the usage of the sparkle model for both PM3 and AM1 for the prediction of lanthanide complexes geometries. 
Table S1. Values of the coordination numbers, CNs, and unsigned mean errors, $\mathrm{UME}_{(\mathrm{Eu}-\mathrm{L})}$ s, and UMEs, for Sparkle/PM3 and Sparkle/AM1, as compared to the respective experimental crystallographic values, obtained from the Cambridge Structural Database, for each of the ninety-six europium (III) complexes

\begin{tabular}{|c|c|c|c|c|c|}
\hline \multirow{2}{*}{ Structure $^{\mathrm{a}}$} & \multirow{2}{*}{$\mathrm{CN}$} & \multicolumn{2}{|c|}{ Sparkle $\mathrm{UME}_{(\mathrm{Eu}-\mathrm{L})} / \AA$} & \multicolumn{2}{|c|}{ Sparkle UME / } \\
\hline & & PM3 & AM1 & PM3 & AM1 \\
\hline ACPNEU & 8 & 0.078 & 0.042 & 0.171 & 0.171 \\
\hline BAFZEO & 9 & 0.072 & 0.106 & 0.129 & 0.132 \\
\hline BAPXAR & 9 & 0.068 & 0.005 & 0.140 & 0.093 \\
\hline BEKWUJ & 11 & 0.087 & 0.163 & 0.151 & 0.234 \\
\hline BUVXAR11 & 9 & 0.078 & 0.049 & 0.200 & 0.242 \\
\hline CEXKUL & 9 & 0.094 & 0.144 & 0.137 & 0.221 \\
\hline CEXKUL01 & 9 & 0.061 & 0.049 & 0.112 & 0.104 \\
\hline CEYRON & 10 & 0.076 & 0.115 & 0.177 & 0.225 \\
\hline CIRKET & 8 & 0.073 & 0.025 & 0.151 & 0.267 \\
\hline COZLEI10 & 8 & 0.095 & 0.084 & 0.166 & 0.212 \\
\hline DIWNOM & 10 & 0.072 & 0.121 & 0.312 & 0.341 \\
\hline DOFXIF & 9 & 0.067 & 0.022 & 0.133 & 0.099 \\
\hline DOPCEQ & 9 & 0.086 & 0.123 & 0.134 & 0.224 \\
\hline DUCNAQ & 9 & 0.077 & 0.110 & 0.121 & 0.210 \\
\hline ECABOZ & 10 & 0.077 & 0.115 & 0.154 & 0.205 \\
\hline EGOBEH & 9 & 0.071 & 0.090 & 0.101 & 0.124 \\
\hline FETGUG & 8 & 0.082 & 0.063 & 0.250 & 0.248 \\
\hline FOCQOD & 9 & 0.084 & 0.062 & 0.160 & 0.189 \\
\hline FOCQUJ & 9 & 0.067 & 0.056 & 0.121 & 0.129 \\
\hline FOCREU & 9 & 0.110 & 0.103 & 0.198 & 0.304 \\
\hline FUXPOD & 9 & 0.027 & 0.075 & 0.294 & 0.255 \\
\hline FUZZOP & 8 & 0.060 & 0.059 & 0.275 & 0.212 \\
\hline GACJOJ & 10 & 0.106 & 0.172 & 0.089 & 0.188 \\
\hline GAPRUK & 8 & 0.021 & 0.049 & 0.052 & 0.087 \\
\hline GEBYAN & 9 & 0.085 & 0.110 & 0.097 & 0.175 \\
\hline GINPIC & 9 & 0.053 & 0.061 & 0.149 & 0.198 \\
\hline HANBIH & 9 & 0.058 & 0.031 & 0.147 & 0.204 \\
\hline HAZGAQ & 8 & 0.030 & 0.052 & 0.051 & 0.077 \\
\hline JAXXOV & 8 & 0.094 & 0.052 & 0.150 & 0.135 \\
\hline JUCZIQ & 9 & 0.054 & 0.063 & 0.177 & 0.218 \\
\hline JUDBOZ & 9 & 0.098 & 0.080 & 0.218 & 0.265 \\
\hline JUGBUI & 10 & 0.071 & 0.128 & 0.123 & 0.175 \\
\hline KAFDOK & 9 & 0.046 & 0.043 & 0.132 & 0.166 \\
\hline KAKPAN & 8 & 0.077 & 0.037 & 0.362 & 0.345 \\
\hline KELNOE & 8 & 0.063 & 0.041 & 0.350 & 0.197 \\
\hline KIFKOZ02 & 9 & 0.051 & 0.071 & 0.105 & 0.115 \\
\hline KIHSEZ & 10 & 0.076 & 0.107 & 0.119 & 0.164 \\
\hline LAPJAN & 10 & 0.062 & 0.092 & 0.110 & 0.168 \\
\hline LEJTAV & 8 & 0.067 & 0.042 & 0.154 & 0.234 \\
\hline LELRUP & 8 & 0.100 & 0.056 & 0.187 & 0.134 \\
\hline LOWBEE & 10 & 0.100 & 0.088 & 0.136 & 0.151 \\
\hline LUHFUP & 9 & 0.092 & 0.105 & 0.137 & 0.153 \\
\hline LUHGAW & 9 & 0.093 & 0.101 & 0.122 & 0.142 \\
\hline MASKAS & 8 & 0.072 & 0.026 & 0.228 & 0.194 \\
\hline MEBDUS & 9 & 0.095 & 0.110 & 0.141 & 0.195 \\
\hline MIHNOG & 8 & 0.073 & 0.027 & 0.134 & 0.132 \\
\hline MIHPOI & 9 & 0.066 & 0.054 & 0.109 & 0.157 \\
\hline MOYJUF & 9 & 0.078 & 0.101 & 0.110 & 0.140 \\
\hline
\end{tabular}

\begin{tabular}{|c|c|c|c|c|c|}
\hline \multirow{2}{*}{ Structure $^{\mathrm{a}}$} & \multirow{2}{*}{$\mathrm{CN}$} & \multicolumn{2}{|c|}{ Sparkle $\mathrm{UME}_{(\mathrm{Eu}-\mathrm{L})} / \AA$} & \multicolumn{2}{|c|}{ Sparkle UME / } \\
\hline & & PM3 & AM1 & PM3 & AM1 \\
\hline MUHROW & 9 & 0.097 & 0.102 & 0.138 & 0.141 \\
\hline MUHRUC & 9 & 0.095 & 0.101 & 0.168 & 0.240 \\
\hline NIGWUV & 9 & 0.065 & 0.077 & 0.097 & 0.156 \\
\hline NOHLUR & 9 & 0.047 & 0.037 & 0.109 & 0.145 \\
\hline NUXHIX & 7 & 0.103 & 0.143 & 0.159 & 0.225 \\
\hline PHASEU & 10 & 0.079 & 0.144 & 0.123 & 0.199 \\
\hline PUHYEW01 & 10 & 0.087 & 0.128 & 0.129 & 0.245 \\
\hline PIEUAC01 & 8 & 0.061 & 0.023 & 0.208 & 0.144 \\
\hline PITCUQ & 8 & 0.074 & 0.042 & 0.358 & 0.174 \\
\hline QAKWUU & 8 & 0.065 & 0.032 & 0.133 & 0.145 \\
\hline QALFEO & 9 & 0.089 & 0.100 & 0.230 & 0.276 \\
\hline QALFOY & 8 & 0.047 & 0.040 & 0.182 & 0.208 \\
\hline QECGOU & 6 & 0.124 & 0.066 & 0.256 & 0.211 \\
\hline QHDOEU & 7 & 0.101 & 0.045 & 0.186 & 0.152 \\
\hline QIGJAR & 9 & 0.201 & 0.188 & 0.228 & 0.215 \\
\hline QIMREJ & 10 & 0.082 & 0.129 & 0.303 & 0.202 \\
\hline QIQHAZ & 9 & 0.131 & 0.128 & 0.291 & 0.350 \\
\hline QUBWUF & 10 & 0.053 & 0.138 & 0.154 & 0.205 \\
\hline SOPFUY & 9 & 0.037 & 0.020 & 0.113 & 0.102 \\
\hline SUXXIS & 12 & 0.076 & 0.230 & 0.117 & 0.313 \\
\hline TMHPEU10 & 8 & 0.100 & 0.059 & 0.132 & 0.127 \\
\hline TOKMUB & 8 & 0.080 & 0.121 & 0.099 & 0.142 \\
\hline TUQTOO & 9 & 0.100 & 0.065 & 0.239 & 0.274 \\
\hline VUSGOF & 9 & 0.090 & 0.124 & 0.116 & 0.307 \\
\hline WAVNUC & 9 & 0.056 & 0.077 & 0.105 & 0.094 \\
\hline WELBUK & 11 & 0.065 & 0.173 & 0.294 & 0.274 \\
\hline WOMCIK & 9 & 0.060 & 0.092 & 0.095 & 0.133 \\
\hline XECLEW & 9 & 0.085 & 0.094 & 0.155 & 0.226 \\
\hline XECLIA & 8 & 0.204 & 0.071 & 0.318 & 0.209 \\
\hline XICHIA & 8 & 0.072 & 0.068 & 0.188 & 0.098 \\
\hline XICHOG & 8 & 0.082 & 0.068 & 0.083 & 0.085 \\
\hline XICHUM & 8 & 0.094 & 0.078 & 0.078 & 0.077 \\
\hline XIHQIO & 9 & 0.192 & 0.205 & 0.142 & 0.171 \\
\hline XILGII & 9 & 0.070 & 0.076 & 0.118 & 0.123 \\
\hline XIWTAY & 9 & 0.095 & 0.103 & 0.145 & 0.199 \\
\hline XIWTUS & 8 & 0.085 & 0.050 & 0.145 & 0.120 \\
\hline YEZFAK & 8 & 0.069 & 0.031 & 0.153 & 0.186 \\
\hline YICSEI & 8 & 0.107 & 0.103 & 0.136 & 0.122 \\
\hline YODYIZ & 8 & 0.057 & 0.041 & 0.107 & 0.149 \\
\hline YOJDIK & 8 & 0.073 & 0.031 & 0.161 & 0.131 \\
\hline YUXREO & 9 & 0.080 & 0.103 & 0.173 & 0.245 \\
\hline ZAMHOK & 9 & 0.042 & 0.055 & 0.262 & 0.291 \\
\hline ZACXAC & 9 & 0.061 & 0.033 & 0.132 & 0.132 \\
\hline ZESSUL & 8 & 0.123 & 0.095 & 0.136 & 0.159 \\
\hline ZEXJUH & 8 & 0.068 & 0.055 & 0.119 & 0.161 \\
\hline ZIDCUK & 8 & 0.107 & 0.121 & 0.177 & 0.184 \\
\hline ZUCCIJ & 8 & 0.071 & 0.070 & 0.129 & 0.133 \\
\hline
\end{tabular}


Table S2. Values of the coordination numbers, CNs, and unsigned mean errors, $\mathrm{UME}_{(\mathrm{Gd}-\mathrm{L})}$ s, and UMEs, for Sparkle/PM3 and Sparkle/AM1, as compared to the respective experimental crystallographic values, obtained from the Cambridge Structural Database, for each of the seventy gadolinium (III) complexes

\begin{tabular}{|c|c|c|c|c|c|}
\hline \multirow{2}{*}{ Structure $^{\mathrm{a}}$} & \multirow{2}{*}{$\mathrm{CN}$} & \multicolumn{2}{|c|}{ Sparkle UME $E_{(\mathrm{Eu}-\mathrm{L})} / \AA$} & \multicolumn{2}{|c|}{ Sparkle UME / } \\
\hline & & PM3 & $\mathrm{AM} 1$ & PM3 & AM1 \\
\hline ACAQGD & 9 & 0.081 & 0.085 & 0.113 & 0.156 \\
\hline ADUPEU & 7 & 0.153 & 0.116 & 0.092 & 0.088 \\
\hline BIFZEV & 9 & 0.043 & 0.034 & 0.302 & 0.290 \\
\hline BUVVOD & 9 & 0.068 & 0.061 & 0.169 & 0.283 \\
\hline BUVVOD01 & 9 & 0.065 & 0.058 & 0.081 & 0.277 \\
\hline COSTAF & 9 & 0.130 & 0.136 & 0.288 & 0.462 \\
\hline CULNIG10 & 7 & 0.100 & 0.097 & 0.196 & 0.236 \\
\hline DIQBIO & 10 & 0.104 & 0.093 & 0.182 & 0.186 \\
\hline DIYNEE & 8 & 0.030 & 0.024 & 0.219 & 0.230 \\
\hline DUFBEL & 8 & 0.030 & 0.026 & 0.110 & 0.156 \\
\hline EHAXEQ & 8 & 0.073 & 0.062 & 0.103 & 0.099 \\
\hline FONMEA & 8 & 0.062 & 0.057 & 0.124 & 0.154 \\
\hline FUHQUU & 9 & 0.035 & 0.029 & 0.090 & 0.096 \\
\hline FUXPUJ & 9 & 0.024 & 0.026 & 0.131 & 0.258 \\
\hline GAKYAS & 8 & 0.033 & 0.026 & 0.194 & 0.227 \\
\hline GAWBEL & 8 & 0.024 & 0.030 & 0.083 & 0.097 \\
\hline GEGCIE & 9 & 0.046 & 0.038 & 0.069 & 0.066 \\
\hline GIDQUF & 8 & 0.072 & 0.037 & 0.103 & 0.066 \\
\hline GINPOI & 9 & 0.051 & 0.057 & 0.096 & 0.285 \\
\hline GIRKUN & 9 & 0.089 & 0.101 & 0.103 & 0.352 \\
\hline GODMER & 10 & 0.095 & 0.101 & 0.148 & 0.236 \\
\hline HEDMIM & 9 & 0.061 & 0.067 & 0.120 & 0.198 \\
\hline JARBUZ & 9 & 0.068 & 0.078 & 0.138 & 0.153 \\
\hline JOPJIH & 9 & 0.061 & 0.063 & 0.100 & 0.142 \\
\hline JOPJIH01 & 9 & 0.042 & 0.040 & 0.066 & 0.090 \\
\hline LANITB & 9 & 0.056 & 0.071 & 0.256 & 0.310 \\
\hline LASZOU & 9 & 0.028 & 0.027 & 0.110 & 0.094 \\
\hline LASZIO & 9 & 0.191 & 0.246 & 0.283 & 0.463 \\
\hline LEJVEB & 8 & 0.035 & 0.025 & 0.156 & 0.254 \\
\hline LOKNEE & 9 & 0.057 & 0.056 & 0.127 & 0.135 \\
\hline LOQKEH & 9 & 0.055 & 0.039 & 0.077 & 0.092 \\
\hline MIPTOU & 7 & 0.140 & 0.103 & 0.068 & 0.063 \\
\hline NAVWIQ & 9 & 0.090 & 0.104 & 0.135 & 0.185 \\
\hline NIGHEQ & 10 & 0.055 & 0.039 & 0.100 & 0.061 \\
\hline NIGXAC & 9 & 0.070 & 0.056 & 0.099 & 0.105 \\
\hline NIVQEO & 8 & 0.053 & 0.048 & 0.123 & 0.141 \\
\hline
\end{tabular}

\begin{tabular}{|c|c|c|c|c|c|}
\hline \multirow{2}{*}{ Structure ${ }^{a}$} & \multirow{2}{*}{$\mathrm{CN}$} & \multicolumn{2}{|c|}{ Sparkle $\mathrm{UME}_{(\mathrm{Eu}-\mathrm{L})} / \AA$} & \multicolumn{2}{|c|}{ Sparkle UME / $\AA$} \\
\hline & & PM3 & AM1 & PM3 & AM1 \\
\hline PADEGA10 & 10 & 0.054 & 0.077 & 0.099 & 0.120 \\
\hline PALHAL & 8 & 0.131 & 0.109 & 0.140 & 0.126 \\
\hline PEBDOP & 9 & 0.050 & 0.042 & 0.246 & 0.229 \\
\hline PROPGD & 8 & 0.060 & 0.062 & 0.137 & 0.197 \\
\hline PUZHUN & 10 & 0.074 & 0.094 & 0.106 & 0.134 \\
\hline SERYOD & 8 & 0.053 & 0.068 & 0.101 & 0.301 \\
\hline TUFLUB & 9 & 0.051 & 0.048 & 0.168 & 0.241 \\
\hline UDOMIJ & 9 & 0.049 & 0.040 & 0.179 & 0.097 \\
\hline UDOMOP & 9 & 0.043 & 0.043 & 0.118 & 0.096 \\
\hline VEDSEC & 10 & 0.077 & 0.060 & 0.112 & 0.089 \\
\hline VETDON & 9 & 0.047 & 0.039 & 0.096 & 0.094 \\
\hline VIGBOC & 9 & 0.053 & 0.046 & 0.073 & 0.086 \\
\hline WALQAB & 9 & 0.038 & 0.032 & 0.081 & 0.093 \\
\hline WAVPAK & 9 & 0.052 & 0.068 & 0.218 & 0.140 \\
\hline WAXCIH & 9 & 0.084 & 0.067 & 0.125 & 0.155 \\
\hline WEWNOB & 6 & 0.050 & 0.017 & 0.084 & 0.051 \\
\hline WIRTUM & 5 & 0.086 & 0.094 & 0.111 & 0.127 \\
\hline WUCCOM & 9 & 0.084 & 0.069 & 0.180 & 0.158 \\
\hline XIVFOX & 8 & 0.069 & 0.031 & 0.135 & 0.018 \\
\hline XUBGUW & 10 & 0.057 & 0.073 & 0.094 & 0.096 \\
\hline YAVSUJ & 9 & 0.079 & 0.087 & 0.149 & 0.344 \\
\hline YEGTOT & 8 & 0.007 & 0.005 & 0.081 & 0.093 \\
\hline YEWGEM & 8 & 0.089 & 0.082 & 0.110 & 0.136 \\
\hline YIYLAT & 9 & 0.038 & 0.053 & 0.093 & 0.122 \\
\hline YOVFIY01 & 9 & 0.034 & 0.027 & 0.102 & 0.109 \\
\hline YUWZOF & 6 & 0.028 & 0.044 & 0.177 & 0.185 \\
\hline ZAXQAQ & 8 & 0.033 & 0.034 & 0.136 & 0.224 \\
\hline ZAZQEW & 8 & 0.007 & 0.006 & 0.065 & 0.086 \\
\hline ZENGUU & 6 & 0.101 & 0.119 & 0.136 & 0.157 \\
\hline ZIPJIR & 9 & 0.043 & 0.036 & 0.122 & 0.146 \\
\hline ZIZNUR & 8 & 0.055 & 0.051 & 0.147 & 0.150 \\
\hline ZUNCAM & 8 & 0.112 & 0.097 & 0.103 & 0.110 \\
\hline ZZZARA01 & 9 & 0.063 & 0.055 & 0.174 & 0.265 \\
\hline
\end{tabular}

${ }^{a}$ The structures are identified by their respective codes of reference from the Cambridge Structural Database. 
Table S3. Values of the coordination numbers, CNs, and unsigned mean errors, UME ${ }_{(\mathrm{Tb}-\mathrm{L})} \mathrm{s}$ and UMEs, for Sparkle/PM3 and Sparkle/AM1, as compared to the respective experimental crystallographic values, obtained from the Cambridge Structural Database, for each of the forty-two terbium (III) complexes

\begin{tabular}{|c|c|c|c|c|c|}
\hline \multirow{2}{*}{ Structure $^{a}$} & \multirow{2}{*}{$\mathrm{CN}$} & \multicolumn{2}{|c|}{ Sparkle UME $_{(\mathrm{Eu}-\mathrm{L})} / \AA$} & \multicolumn{2}{|c|}{ Sparkle UME / Å } \\
\hline & & PM3 & AM1 & PM3 & AM1 \\
\hline$\overline{B A C B U C}$ & 9 & 0.130 & 0.156 & 0.187 & 0.234 \\
\hline BAFWUB & 9 & 0.040 & 0.035 & 0.110 & 0.138 \\
\hline BAFZOY & 9 & 0.079 & 0.096 & 0.132 & 0.127 \\
\hline BUVXEV01 & 9 & 0.070 & 0.051 & 0.171 & 0.206 \\
\hline COSVOV & 9 & 0.130 & 0.134 & 0.140 & 0.370 \\
\hline CULSEH & 8 & 0.052 & 0.053 & 0.129 & 0.118 \\
\hline DIFHEF & 8 & 0.062 & 0.034 & 0.100 & 0.092 \\
\hline DUCQEX & 9 & 0.070 & 0.085 & 0.129 & 0.166 \\
\hline FAGZAP & 8 & 0.044 & 0.029 & 0.196 & 0.250 \\
\hline FOPPUV & 9 & 0.053 & 0.046 & 0.146 & 0.155 \\
\hline HANBUT & 9 & 0.027 & 0.030 & 0.130 & 0.180 \\
\hline IDOZEG & 9 & 0.088 & 0.100 & 0.128 & 0.139 \\
\hline JAXWOU01 & 8 & 0.093 & 0.116 & 0.186 & 0.241 \\
\hline JAXWOU & 9 & 0.077 & 0.097 & 0.199 & 0.246 \\
\hline JEXWOY & 9 & 0.031 & 0.034 & 0.112 & 0.117 \\
\hline KITGAV & 9 & 0.032 & 0.021 & 0.140 & 0.219 \\
\hline KUYBEL & 9 & 0.025 & 0.050 & 0.230 & 0.245 \\
\hline LEJTEZ & 8 & 0.031 & 0.038 & 0.178 & 0.180 \\
\hline LEYHOM & 9 & 0.028 & 0.074 & 0.177 & 0.244 \\
\hline LIFJEP & 10 & 0.070 & 0.092 & 0.125 & 0.147 \\
\hline MIHNUM & 8 & 0.060 & 0.027 & 0.121 & 0.137 \\
\hline MIHPIC & 8 & 0.056 & 0.028 & 0.121 & 0.137 \\
\hline MIWTAN & 10 & 0.078 & 0.083 & 0.115 & 0.150 \\
\hline NASTUW & 10 & 0.076 & 0.097 & 0.108 & 0.135 \\
\hline NAXRAF & 10 & 0.099 & 0.102 & 0.141 & 0.143 \\
\hline NIGYUX & 9 & 0.065 & 0.063 & 0.105 & 0.136 \\
\hline PAGBOO & 4 & 0.059 & 0.043 & 0.071 & 0.055 \\
\hline PEJZAF & 8 & 0.027 & 0.023 & 0.189 & 0.163 \\
\hline QALFUE & 8 & 0.029 & 0.029 & 0.194 & 0.162 \\
\hline QAWHIF & 8 & 0.065 & 0.049 & 0.081 & 0.079 \\
\hline SEGVEF & 8 & 0.020 & 0.018 & 0.089 & 0.058 \\
\hline TOKVIY & 9 & 0.095 & 0.123 & 0.117 & 0.173 \\
\hline VAPTEL01 & 6 & 0.154 & 0.120 & 0.212 & 0.181 \\
\hline VAPTEL & 6 & 0.165 & 0.131 & 0.227 & 0.166 \\
\hline XARXET & 8 & 0.055 & 0.059 & 0.270 & 0.228 \\
\hline XAXXUP & 7 & 0.092 & 0.064 & 0.167 & 0.176 \\
\hline XEXJIT & 7 & 0.118 & 0.084 & 0.111 & 0.103 \\
\hline XOCDIC & 8 & 0.070 & 0.084 & 0.152 & 0.202 \\
\hline XORGAM & 8 & 0.061 & 0.052 & 0.434 & 0.292 \\
\hline XUGBUW & 7 & 0.092 & 0.074 & 0.161 & 0.183 \\
\hline ZUNCEQ & 8 & 0.107 & 0.096 & 0.115 & 0.124 \\
\hline ZZZARD01 & 9 & 0.068 & 0.051 & 0.173 & 0.244 \\
\hline
\end{tabular}

The structures are identified by their respective codes of reference from the Cambridge Structural Database.
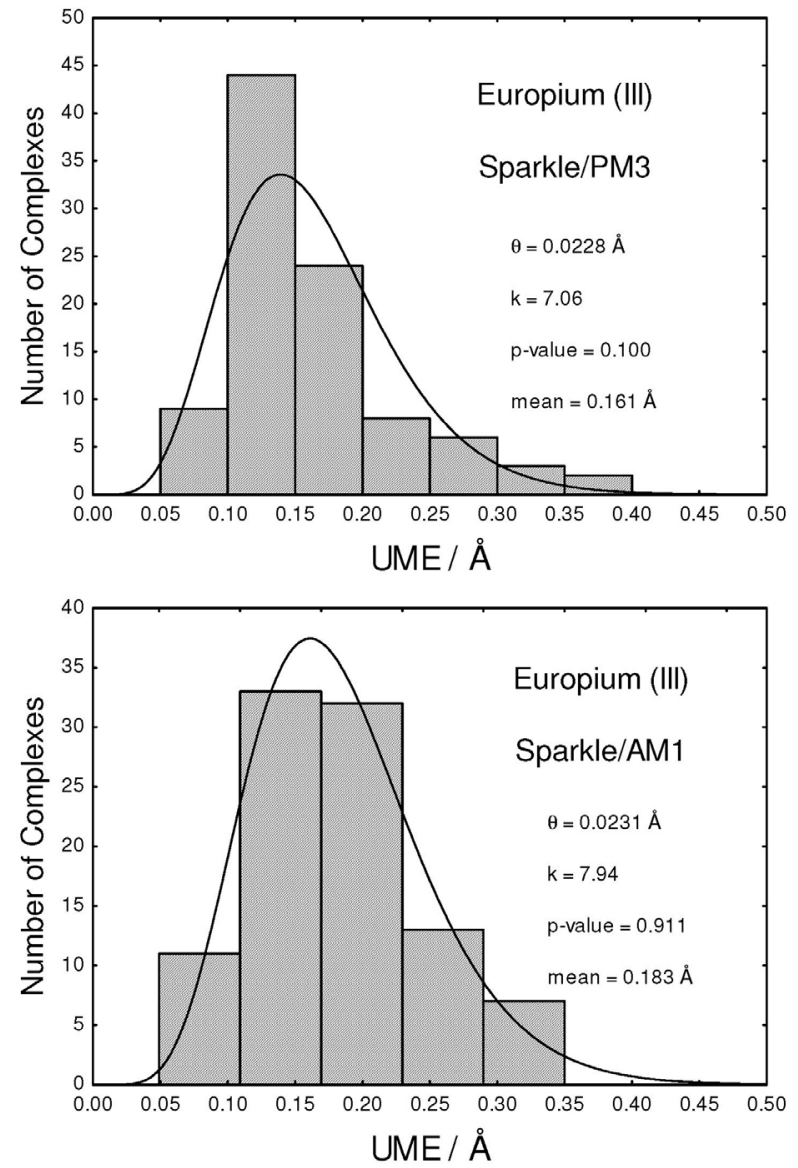

Figure S1. Probability densities of the Gamma distribution fits of the UMEs for the Eu(III) Sparkle/PM3 and Sparkle/AM1 models, superimposed to histograms of the same data for all $96 \mathrm{Eu}$ (III) complexes considered; where $\mathrm{k}$ is the shape parameter and $\theta$ is the scale parameter of the gamma distribution; $\mathrm{p}$-value is a measure of the significance of the gamma distribution fit; and mean is the expected value of the fitted gamma distribution, which is set to be equal to the arithmetic mean value of the 96 UMEs. 

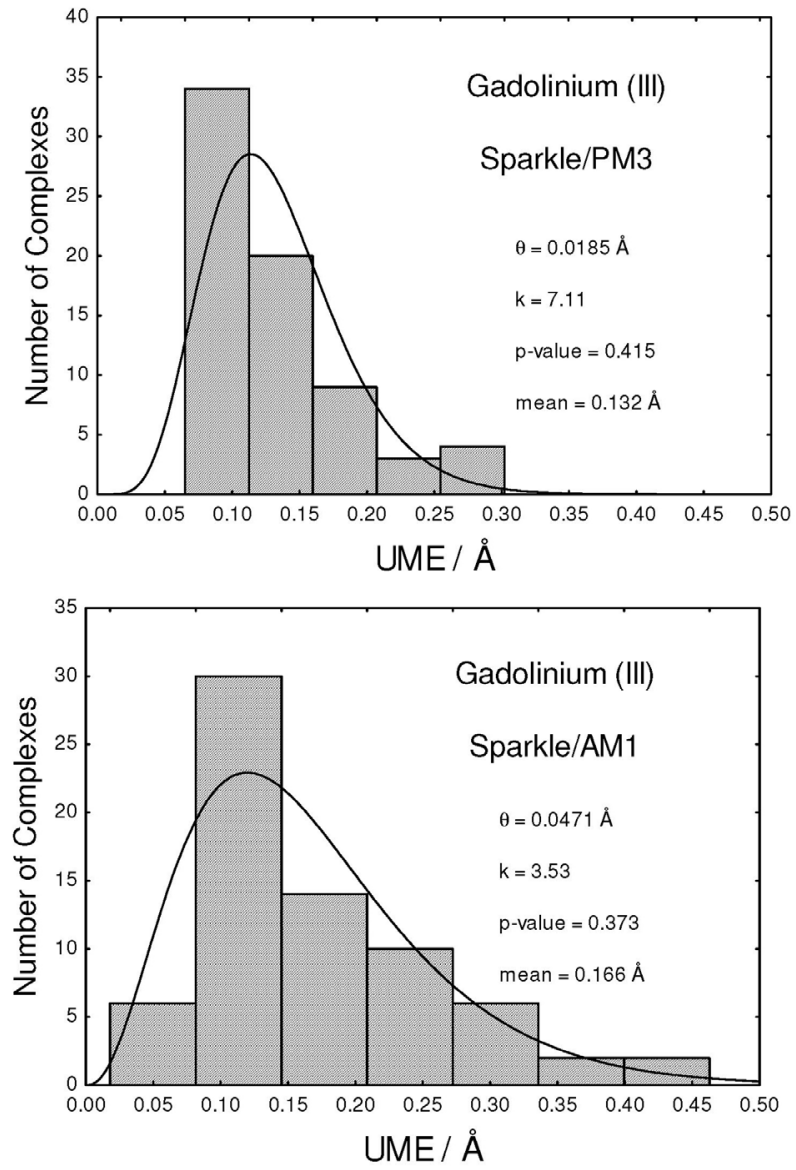

Figure S2. Probability densities of the Gamma distribution fits of the UMEs for the Gd(III) Sparkle/PM3 and Sparkle/AM1 models, superimposed to histograms of the same data for all $70 \mathrm{Gd}$ (III) complexes considered; where $\mathrm{k}$ is the shape parameter and $\theta$ is the scale parameter of the gamma distribution; $\mathrm{p}$-value is a measure of the significance of the gamma distribution fit; and mean is the expected value of the fitted gamma distribution, which is set to be equal to the arithmetic mean value of the 70 UMEs.
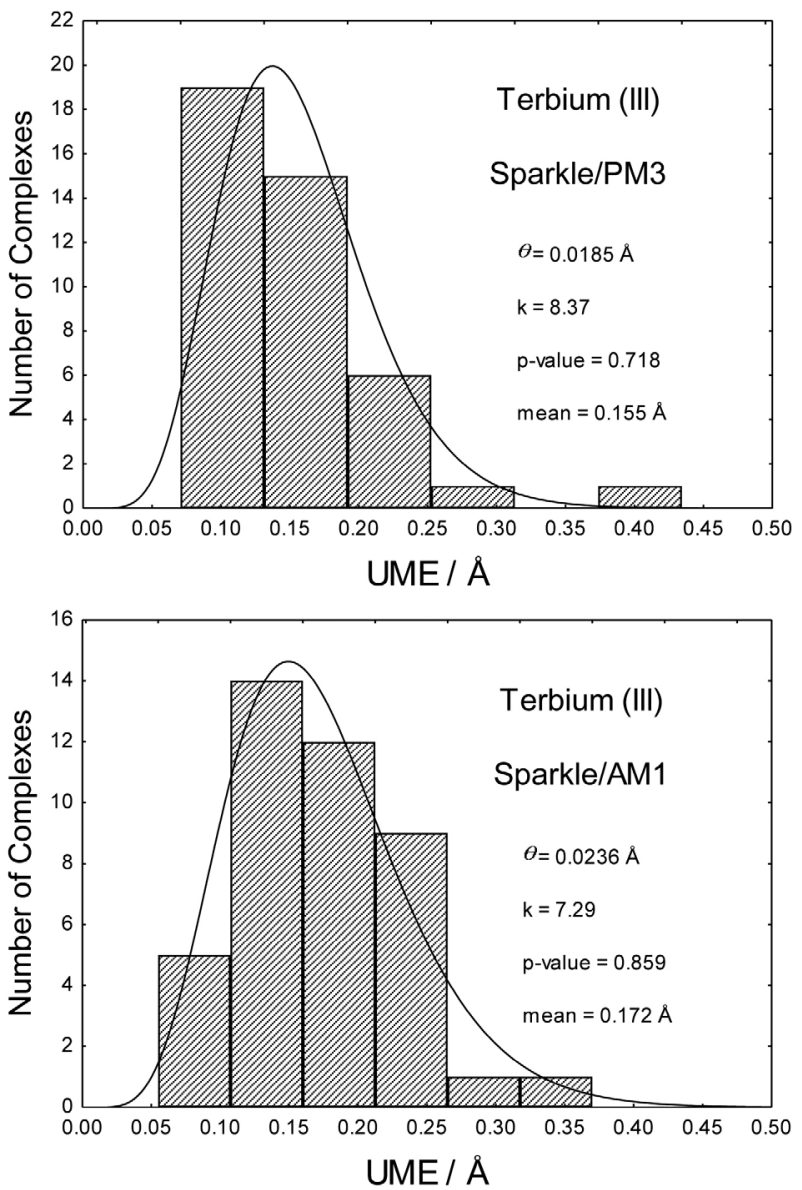

Figure S3. Probability densities of the Gamma distribution fits of the UMEs for the $\mathrm{Tb}$ (III) Sparkle/PM3 and Sparkle/AM1 models, uperimposed to histograms of the same data for all $42 \mathrm{~Tb}$ (III) complexes considered; where $\mathrm{k}$ is the shape parameter and $\theta$ is the scale parameter of the gamma distribution; $\mathrm{p}$-value is a measure of the significance of the gamma distribution fit; and mean is the expected value of the fitted gamma distribution, which is set to be equal to the arithmetic mean value of the 42 UMEs.

\section{References}

1. Freire, R.O.; Rocha, G.B.; Simas, A.M.; Inorg. Chem. 2005, 44, 3299. 